\title{
Article \\ Calendula arvensis (Vaill.) L.: A Systematic Plant Analysis of the Polar Extracts from Its Organs by UHPLC-HRMS
}

\author{
Marika Fiorentino, Claudia Gravina, Simona Piccolella (D), Maria Tommasina Pecoraro, Marialuisa Formato (D), \\ Adriano Stinca (D), Severina Pacifico*(D) and Assunta Esposito (D)
}

Department of Environmental Biological and Pharmaceutical Sciences and Technologies, University of Campania "Luigi Vanvitelli", Via Vivaldi 43, 81100 Caserta, Italy; marika.fiorentino@unicampania.it (M.F.); claudia.gravina@unicampania.it (C.G.); simona.piccolella@unicampania.it (S.P.); mariatommasina.pecoraro@unicampania.it (M.T.P.); marialuisa.formato@unicampania.it (M.F.); adriano.stinca@unicampania.it (A.S.); assunta.esposito@unicampania.it (A.E.)

* Correspondence: severina.pacifico@unicampania.it

\section{check for}

updates

Citation: Fiorentino, M.; Gravina, C.; Piccolella, S.; Pecoraro, M.T.;

Formato, M.; Stinca, A.; Pacifico, S.; Esposito, A. Calendula arvensis (Vaill.) L.: A Systematic Plant Analysis of the Polar Extracts from Its Organs by UHPLC-HRMS. Foods 2022, 11, 247. https://doi.org/10.3390/

foods11030247

Academic Editor:

Antonella De Leonardis

Received: 22 December 2021

Accepted: 13 January 2022

Published: 18 January 2022

Publisher's Note: MDPI stays neutral with regard to jurisdictional claims in published maps and institutional affiliations.

Copyright: () 2022 by the authors Licensee MDPI, Basel, Switzerland. This article is an open access article distributed under the terms and conditions of the Creative Commons Attribution (CC BY) license (https:// creativecommons.org/licenses/by/ $4.0 /)$.

\begin{abstract}
Calendula arvensis (Vaill.) L. (field marigold, Asteraceae) is an alimurgic plant, whose flowers and leaves are a common part of local food dishes. The diversity in polar specialized metabolites is herein unraveled, with the aim to further promote and valorize the food use of the plant. To this purpose, following the plant dissection of its organs (florets, fruits, leaves, bracts, stems, and roots), ultrasound assisted maceration has been employed in order to recover phenols and polyphenols. Through an untargeted UHPLC-HR MS (Ultra-High-Performance Liquid Chromatography-HighResolution Mass Spectrometry) approach, and deeper investigation of the fragmentation patterns of each compound by tandem mass spectrometry, the florets' constitution in triterpene saponins and flavonol glycosides has been highlighted, whereas hydroxycinnamoyl compounds are mainly in bracts and fruits. The antiradical and reducing capabilities of the organs' extracts have been assessed, and data acquired have been analyzed by cluster analysis, which allowed bracts and fruits to be observed, despite their negligible food use, as the most active extracts. Chemical and antioxidant data on the diverse organs of field marigold suggest new investigative food and nutraceutical scenarios of this plant, also revalorizing and preserving its traditional uses.
\end{abstract}

Keywords: Calendula arvensis; Asteraceae; UHPLC-QqTOF-MS/MS analysis; flavonoids; triterpene saponins; traditional food; antioxidants

\section{Introduction}

Wild edible plants (WEPs), described as native species naturally growing, have been among the main food ingredients of rural communities linking human life since ancient times [1,2]. In the Mediterranean area, the traditional uses of WEPs were introduced in ancestors' diets for their curative properties, and nowadays, they continue to represent a considerable part of the Mediterranean Diet. WEPs as basic food stuffs in many local folk cuisines [3-7]. The renewed interest in WEPs is largely due to the growing knowledge of the healthy role of phytochemical compounds, so much so that WEPs can be defined as "functional foods", being a good source of bioactive molecules and dietary supplements [8-10]. This is especially true in countries where the native vascular flora is particularly rich, such as Italy [11].

Indeed, the increased interest in ethnobotanical studies of local wild plants $[7,12]$ emerged out of a need to create new products for the food industry with beneficial properties, as well as for sustainable agriculture because of the low impact of their cultivation on the environment [2,13-16]. In this scenario, knowledge of edible plants biodiversity available in the local food tradition, and of new pathways for the eco-sustainable enhancement of food resources, constitute crucial aspects to intercept in marginal or valuable areas (e.g., Nature Reserves and National Parks), in full agreement with the EU's biodiversity 
strategy plan for 2030 [17]. From the ethnobotanical point of view, Asteraceae is one of the most studied angiosperm families $[18,19]$, thanks to their great diversity and wide worldwide distribution [20]. Within this family, the genus Calendula L. currently includes 15 species and several infraspecific taxa [21]; it is the only genus of the tribe Calenduleae in the Mediterranean region, spreading from Macaronesia to South Western (SW) Asia [21].

In the folk tradition, plants of genus Calendula have a long history, being widely used as a curative remedy against several diseases as well as an ingredient in local dishes [22]. Within this genus, Calendula arvensis (Vaill.) L. (known as field marigold) is an herbaceous annual species widely distributed in Europe, northern Africa, SW Asia, and the Macaronesian region, and also naturalized in other temperate regions $[23,24]$. C. arvensis is a monoecious, self-compatible, and polymorphic annual weed. It can be found everywhere, being able to grow in cultivated fields, along roadsides, and in disturbed sites on different soil types $[25,26]$. It has lance-shaped leaves with secretory trichomes, hairy stems, small capitula $(2-3 \mathrm{~cm})$ with yellow ligulate ray florets, and tubulous central florets; the fruits are achenes of three different shapes, the outers are rostrate and cymbiform, while the sub-peripherals are annular. The flowering period ranges from November to May $[23,27,28]$. It is reported that its rostrate and cymbiform achenes are larger and heavier than annular achenes [23]. The adaption to long-range dispersal also distinguish them from annular achenes. Moreover, achenes germinate across a wide temperature range (in light and in darkness). Rostrate and cymbiform achenes produce seedlings best able to emerge from deeper burial depths, and are able to exhibit earlier flowering than seedlings from annular achenes; fruiting also takes place without pollinators. It is a prolific seed producer, forming a persistent seed bank. All these features favor the species establishment and expansion in unpredictable and disturbed habitats [23].

C. arvensis has a long tradition of uses in different Italian regions, where it is utilized as an edible alimurgic plant. In particular, among the diverse plant organs, the flower and leaves are frequently consumed. Literature reports the use of field marigold flower as a boiling vegetable, whereas the leaves are key ingredients in cooking a typical soup [7,29]. Indeed, $C$. arvensis has a dual value. In fact, beyond its use as foodstuff, its role as phytomedicine has been broadly employed [30]. C. arvensis-based decoction are used for treating wounds, contusion, and burns; whereas field marigold tea is known for its antiseptic and astringent properties. Flower-based preparations are suggested for external use to preserve skin firmness, or to counteract skin inflammation, and to regenerate damaged tissues [31-33]. The flower extracts have been also extensively investigated for their antioxidant efficacy and anticandidal, antifungal, and antimicrobial activities [34], whereas the cytotoxic effects against human myeloid cells [34] and breast cancer lines [35] emphasize that the potential benefits for humans from this wild plant could be multidimensional.

Indeed, despite of numerous data on C. arvensis bioactivity, few studies combine it with a deeper investigation of the chemical composition of the plant organ utilized for extraction purposes [30,36,37]. Furthermore, an inappropriate indication of the part used to study biological activity is common in the literature, so much so that the aerial parts are often cited as the investigated plant matrix, without taking care in the botanical characterization of the aerial part that consists of more organs. It is certain that while there are diverse compositive data for field marigold essential oils $[30,36,37]$, few and fragmentary information are reported in relation to phenol compounds [38,39], which are mainly attentive for their benefits to humans. Indeed, considering that the biosynthesis and following accumulation of polyphenols and other specialized metabolites differ in the various plant organs [40-42], in order to achieve a detailed investigation of local C. arvensis to gain insight into the chemical constituents and to promote the sustainable food use of its different organs, plant dissection is herein proposed as preliminary to extraction. The latter was carried out in order to strengthen the recovery of phenols and polyphenols from the six C. arvensis organs, such as florets, fruits, leaves, bracts, stems, and roots. UHPLC-HRMS (Ultra-HighPerformance Liquid Chromatography-High-Resolution Mass Spectrometry) techniques, in an 
untargeted approach, were exploited to unravel the chemical complexity of different organs of $C$. arvensis, as well as antioxidant assessment through three different assays.

\section{Materials and Methods}

\subsection{Plant Material Collection, Organ Separation, and Extraction}

Calendula arvensis plants were collected in May 2021 in southern Italy in the municipality of Roccaromana (Caserta, Italy; $41^{\circ} 16^{\prime} 30.36^{\prime \prime} \mathrm{N} 14^{\circ} 13^{\prime} 19.92^{\prime \prime} \mathrm{E}, 163 \mathrm{~m}$ a.s.1.) (Figure 1A). Taxonomic identification was performed following [28,29]. A voucher specimen (CE0131) has been deposited in the Herbarium of the Department of Environmental, Biological, and Pharmaceutical Sciences and Technologies of the University of Campania Luigi Vanvitelli (Caserta, Italy). Sampled plants came from an uncultivated land colonized mainly by Papaver rhoeas L. subsp. rhoeas and other ruderal species. As per the Bioclimatic map of Europe [43], this territory is located in the transition zone between the Pluvioseasonal Oceanic Mediterranean and Temperate Oceanic Submediterranean bioclimates. From the pedological point of view, soil is a Luvi-Vitric Andosol and is ascribable to the great land system of the "foothills plain of limestone reliefs" [44]. Immediately after harvesting, each plant material was dissected by hand into fruits, ligulate florets (henceforth referred to as florets), receptacle with involucral bracts (throughout the text, indicated as bracts), leaves, stems, and roots, then labeled, and stored in liquid nitrogen (Figure 1A).

(A)

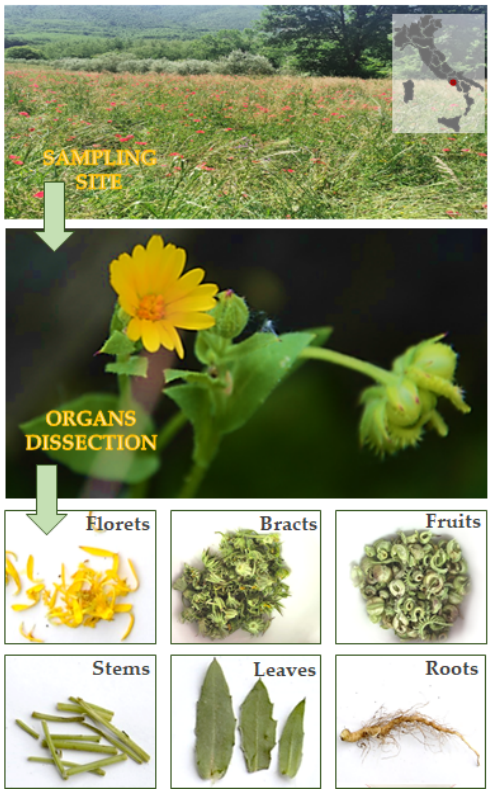

(B)

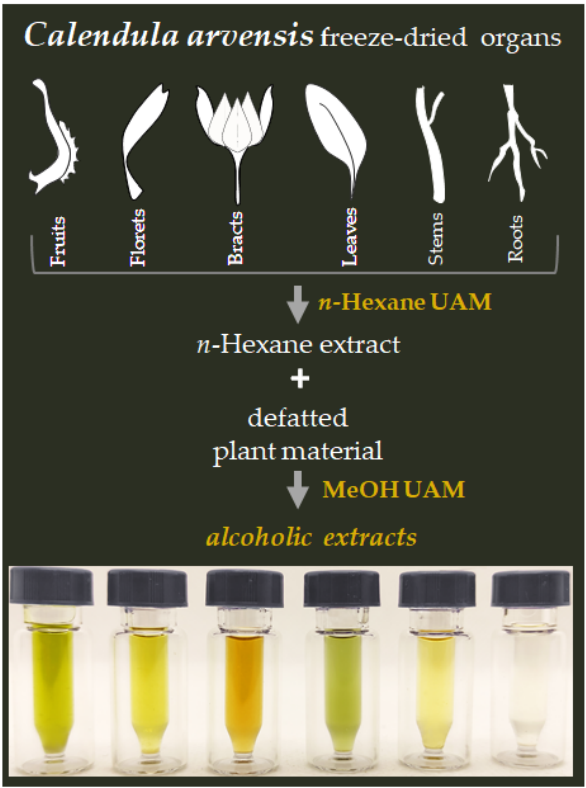

Figure 1. C. arvensis sampling site and organs separation (A); fractionation scheme of the plant's freeze-dried organs $(\mathbf{B})$.

Each plant organ was first lyophilized and pulverized by a rotating knives homogenizer. Dried material underwent ultrasound assisted maceration (UAM; Branson Ultrasonics ${ }^{\mathrm{TM}}$ Bransonic $^{\mathrm{TM}}$ M3800-E; Danbury, CT, USA) using first $n$-hexane and then methanol as extractive solvents. The drug/solvent ratio was 1:20 (g drug: $\mathrm{mL}$ solvent); three UAM cycles by each solvent were carried out (30 min for each; Figure 1B). The alcoholic extracts were chemically analyzed through UHPLC-ESI-QqTOF-MS/MS analysis, and their antioxidant capability was assessed.

\subsection{UHPLC-ESI-QqTOF-MS and MS/MS Analyses}

The alcoholic extracts from $C$. arvensis organs were profiled by a NEXERA UHPLC system (Shimadzu; Tokyo, Japan) equipped with Luna ${ }^{\circledR}$ Omega C-18 columns. A linear gradient was applied for separative purposes with water $(\mathrm{A})$ and acetonitrile (B), both with $0.1 \%$ formic acid: held at 5\%, for $1 \mathrm{~min} ; 1-7 \mathrm{~min}, 5-17.5 \% \mathrm{~B}$; $7-9 \mathrm{~min}, 17.5-25 \% \mathrm{~B}$; $9-18 \mathrm{~min}$, 
25-55\% B; 18-20 min, 55-95\% B. The mobile phase composition was maintained at 95\% B for another $1 \mathrm{~min}$. Thus, the starting conditions were restored in $1 \mathrm{~min}$, while system re-equilibration was in $2 \mathrm{~min}$. The flow rate was $0.5 \mathrm{~mL} / \mathrm{min}$. The injection volume was $2.0 \mu \mathrm{L}$. MS analysis was achieved by the AB SCIEX Triple TOF ${ }^{\circledR} 4600$ (AB Sciex; Concord, ON, Canada), equipped with a DuoSpray ${ }^{\mathrm{TM}}$ ion source, which operated in the negative ESI mode.

The Q $q$ TOF HRMS method consisted of a full scan TOF survey (accumulation time $249.9 \mathrm{~ms}, 100-1500 \mathrm{Da})$ and eight IDA (information-dependent acquisition). The MS parameters were as follows: curtain gas 35 psi, nebulizer gas 60 psi, heated gas 60 psi, ion spray voltage $4.5 \mathrm{kV}$, and interface heater temperature $500{ }^{\circ} \mathrm{C}$. The instrument was controlled by Analyst ${ }^{\circledR}$ TF 1.7 software, while data processing was through PeakView ${ }^{\circledR}$ software version 2.2 .

The TOF-MS/MS parameters for the analysis of flavonoids and hydroxycinnamic and hydroxybenzoic acids were $-100 \mathrm{~V}$ of declustering potential (DP), $-40 \mathrm{~V}$ of Collision energy (CE), and $-15 \mathrm{~V}$ of Collision energy spread (CES). For the characterization of triterpenoid saponins, the parameters were as follows: DP $-120 \mathrm{~V}, \mathrm{CE}-100 \mathrm{~V}$, and CES $-25 \mathrm{~V}$.

\subsection{Antioxidant Assessment}

The alcoholic extracts from $C$. arvensis organs were tested at 100, 50, 25, 10, and $2.5 \mu \mathrm{g} / \mathrm{mL}$ towards the ABTS [2,2'-azinobis-(3-ethylbenzothiazolin-6-sulfonic acid)] radical cation and 2,2-diphenyl-1-picrylhydrazyl (DPPH) radical. The ABTS radical cation was prepared as in Pacifico et al. [45]. After the $\mathrm{ABTS}^{\bullet+}$ solution was diluited in Phosphatebuffered saline (PBS; pH 7.4) to achieve an absorbance of 0.7 , that was recorded at $734 \mathrm{~nm}$. All organ alcoholic extracts were dissolved in the $\mathrm{ABTS}^{\bullet+}$ solution in order to achieve the final tested dose level, and the absorbance values were taken after 6 min by a Victor3 spectrophotometer (Perkin Elmer/Wallac; Waltham, MA, USA). A blank, in which the organ extracts were replaced with solvents, was also prepared.

The DPPH free radical scavenging capacity was also evaluated as previously described [45]. The Victor3 spectrophotometer (Perkin Elmer/Wallac; Waltham, MA, USA) was employed for recording the absorbance at $517 \mathrm{~nm}$. A blank, in which methanolic extracts were replaced with solvents, was used as a reference. In both the antiradical assays, Trolox $(4,8,16,32 \mu \mathrm{M})$ was the positive standard. Three replicate measurements for each samples (three for each concentration) were performed.

The potassium ferricyanide reducing power (PFRAP) assay was also performed to estimate the reducing power of the investigated alcoholic extracts (at 100,50, 25, 10, and $2.5 \mu \mathrm{g} / \mathrm{mL}$ final concentration levels). The absorbance was measured at $700 \mathrm{~nm}[46,47]$. A blank was considered, preparing a solution with PFRAP reagent without samples, as well as Trolox as a positive standard.

All data were expressed as the mean \pm standard deviation (SD).

\subsection{Statistical Analysis}

A multivariate analysis approach by ClustVis (https:/ / biit.cs.ut.ee/clustvis/, accessed on 20 October 2021) was adopted to explore and clarify quali-quantitative compositive data compounds in each organ.

Numerical clustering of antioxidant assay (DPPH, ABTS, and PFRAP) data was made on the basis of mean values of three replicates for each of five extract concentrations tested for each of the six C. arvensis organs (fruits, florets, bracts, stems, leaves, and roots), using the SYN-TAX software [48].

\section{Results and Discussion}

\subsection{UHPLC-QqTOF-MS/MS Analysis of Calendula arvensis (Vaill.) L.}

To investigate the chemical composition, mainly in terms of polyphenols, of the diverse organs (florets, fruits, bracts, leaves, stems, and roots) of C. arvensis, the cryo-dried plant materials underwent ultrasound assisted maceration first in $n$-hexane, to remove 
more lipophilic components (e.g., fatty acids). Thus, the defatted plant matrices were then extracted with methanol. The alcoholic extracts obtained, were analysed by means of UHPLC-Q $q$ TOF-MS/MS analysis, taking into account the chemical features of the compounds. The Total Ion Chromatograms (TICs; Figure 2) highlight that hydroxycinnamoylbased compounds, flavonoids, and triterpenoid saponins diversely occurred in the different organs. Different TOF-MS/MS parameters (including collision energy and declustering potential) were utilized in order to reach a comprehensive fragmentation for each identified class of compounds, thus putatively unravelling the compounds' MS/MS chemical features. TOF-MS and TOF-MS/MS data of all the compounds are listed in Table 1.
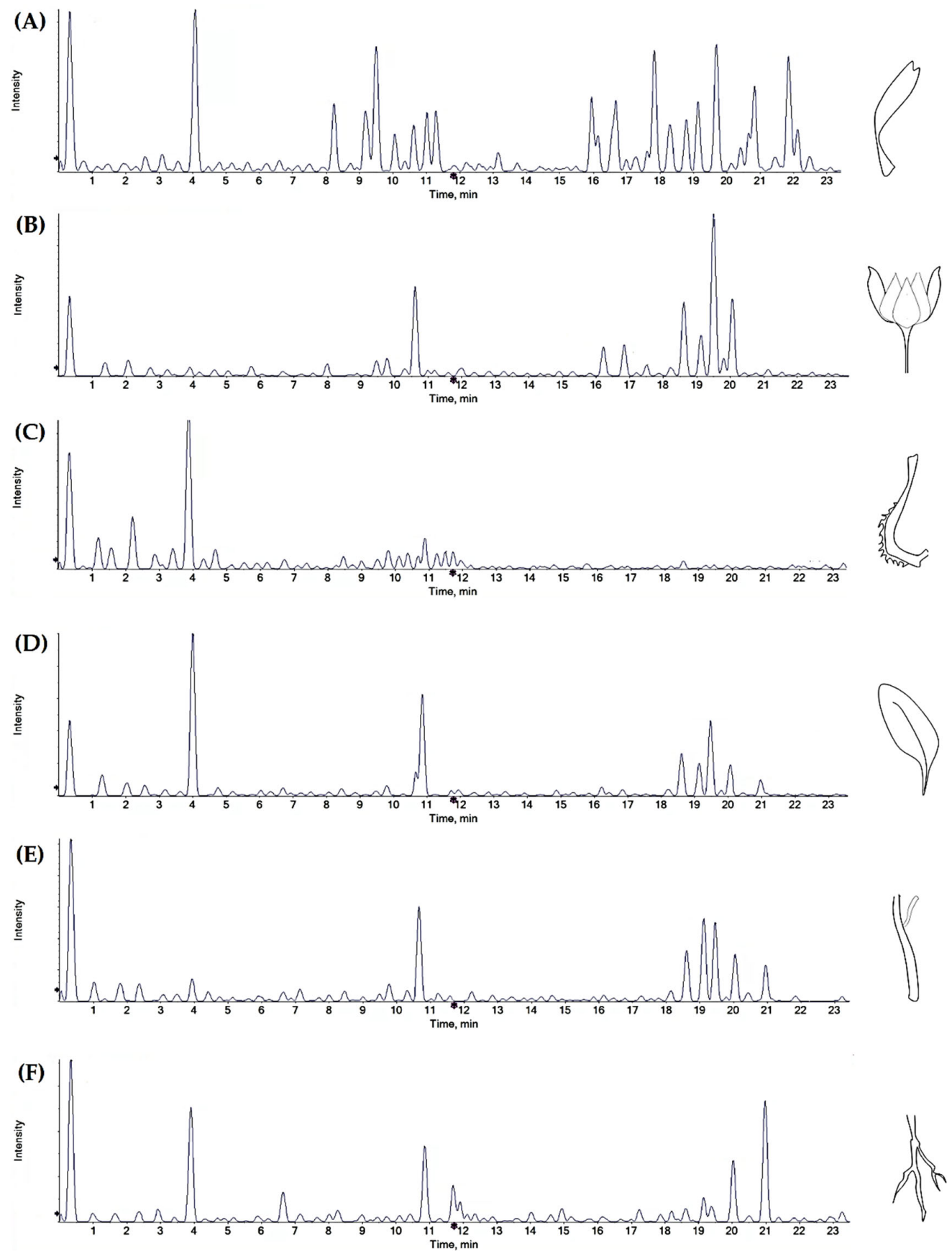

Figure 2. TICs (Total Ion Chromatograms) of the alcoholic extracts from (A) florets, (B) bracts, (C) fruits, (D) leaves, (E) stems, and (F) roots of Calendula arvensis. 
Table 1. Metabolites tentatively identified in the alcoholic extracts from the different organs of Calendula arvensis. RT, Retention Time; RDB, Ring Double Bond equivalent value.

\begin{tabular}{|c|c|c|c|c|c|c|c|c|}
\hline Peak $\mathbf{n}^{\circ}$ & $t_{R}(\min )$ & Formula & RDB & $\begin{array}{l}{[\mathbf{M}-\mathbf{H}]^{-}(m / z)} \\
\text { Found }\end{array}$ & $\begin{array}{l}{[\mathbf{M}-\mathbf{H}]^{-}(m / z)} \\
\text { calcd. }\end{array}$ & ppm & MS/MS $(m / z)$ & Tentative Assignment \\
\hline 1 & 0.311 & $\mathrm{C}_{4} \mathrm{H}_{6} \mathrm{O}_{5}$ & 2.0 & 133.0140 & 133.0142 & -1.9 & $133.0139,115.0036(100)$ & Malic acid \\
\hline 2 & 0.317 & $\mathrm{C}_{7} \mathrm{H}_{12} \mathrm{O}_{6}$ & 2.0 & 191.0557 & 191.0561 & -2.2 & $191.0556(100), 111.0083,93.0344,85.0294$ & Quinic acid \\
\hline 3 & 0.322 & $\mathrm{C}_{12} \mathrm{H}_{22} \mathrm{O}_{11}$ & 2.0 & $\begin{array}{c}341.1108 \\
377.0860 \\
{\left[\mathrm{M}+\mathrm{Cl}^{-}\right]^{-}}\end{array}$ & 341.1089 & -2.2 & $\begin{array}{c}341.1077,179.0562,119.0348,113.0247 \\
89.0247\end{array}$ & Dihexose \\
\hline 4 & 1.174 & $\mathrm{C}_{7} \mathrm{H}_{6} \mathrm{O}_{4}$ & 5.0 & 153.0195 & 153.0193 & 1.1 & $109.0287,108.0335$ & Dihydroxybenzoic acid \\
\hline 5 & 1.824 & $\mathrm{C}_{12} \mathrm{H}_{14} \mathrm{O}_{8}$ & 6.0 & 285.0619 & 285.0616 & 1.1 & $285.0605,153.0190,152.0111,108.0214$ & Pentosyl dihydroxybenzoic acid \\
\hline 6 & 2.080 & $\mathrm{C}_{15} \mathrm{H}_{18} \mathrm{O}_{9}$ & 7.0 & 341.0880 & 341.0878 & 0.6 & $251.0570,179.0354,161.0252(100), 135.0456$ & Caffeoyl hexose \\
\hline 7 & 3.799 & $\mathrm{C}_{16} \mathrm{H}_{18} \mathrm{O}_{9}$ & 8.0 & $\begin{array}{l}353.0886 \\
707.1848\end{array}$ & 353.0878 & 2.2 & $191.0559(100)$ & 5-O-Caffeoylquinic acid (1) \\
\hline 8 & 4.627 & $\mathrm{C}_{16} \mathrm{H}_{18} \mathrm{O}_{9}$ & 8.0 & 353.0877 & 353.0878 & -0.3 & $191.0561(100)$ & 5-O-Caffeoylquinic acid (2) \\
\hline 9 & 6.582 & $\mathrm{C}_{17} \mathrm{H}_{20} \mathrm{O}_{9}$ & 8.0 & 367.1038 & 367.1035 & 0.9 & $193.0513,191.0560(100), 173.0453$ & 5-O-Feruloyl quinic acid \\
\hline 10 & 8.179 & $\mathrm{C}_{27} \mathrm{H}_{30} \mathrm{O}_{17}$ & 13.0 & 625.1414 & 625.1410 & 0.6 & $\begin{array}{c}625.1422(100), 301.0346,300.0269,271.0237 \\
255.0294\end{array}$ & Quercetin-3-O-dihexoside \\
\hline 11 & 8.771 & $\mathrm{C}_{26} \mathrm{H}_{28} \mathrm{O}_{16}$ & 13 & 595.1301 & 595.1305 & -0.6 & $\begin{array}{c}595.1318,301.0349,300.0253,271.0234, \\
255.0291\end{array}$ & Quercetin-3-O-hexosylpentoside \\
\hline 12 & 9.116 & $\mathrm{C}_{27} \mathrm{H}_{30} \mathrm{O}_{16}$ & 13.0 & 609.1472 & 609.1461 & 1.8 & $\begin{array}{c}609.1477,301.0348 \\
300.0270(100), 271.0235,255.0292\end{array}$ & Quercetin-3-O-hexosyldeoxyhexoside \\
\hline 13 & 9.386 & $\mathrm{C}_{21} \mathrm{H}_{20} \mathrm{O}_{12}$ & 12.0 & 463.0882 & 463.0882 & 0 & $\begin{array}{c}463.0905,301.0358 \\
300.0281(100), 271.0253,255.0300 \\
\end{array}$ & Quercetin-3-O-hexoside (1) \\
\hline 14 & 9.326 & $\mathrm{C}_{26} \mathrm{H}_{28} \mathrm{O}_{16}$ & 13.0 & 595.1309 & 595.1305 & 0.7 & $\begin{array}{c}595.1303,463.0916(<5 \%), 301.0340,300.0260 \\
(100), 271.0226,255.0306\end{array}$ & Quercetin-3-O-hexosylpentoside \\
\hline 15 & 9.473 & $\mathrm{C}_{27} \mathrm{H}_{30} \mathrm{O}_{16}$ & 13.0 & 609.1473 & 609.1461 & 1.8 & $\begin{array}{c}609.1484,301.0253 \\
300.0275(100), 271.0246,255.0295\end{array}$ & Rutin \\
\hline 16 & 9.692 & $\mathrm{C}_{21} \mathrm{H}_{20} \mathrm{O}_{12}$ & 12.0 & 463.0883 & 463.0882 & 0.2 & $\begin{array}{c}463.0879,301.0341 \\
300.0267(100), 271.0238,255.0285\end{array}$ & Quercetin-3-O-hexoside (2) \\
\hline
\end{tabular}


Table 1. Cont.

\begin{tabular}{|c|c|c|c|c|c|c|c|c|}
\hline Peak $n^{\circ}$ & $t_{R}(\min )$ & Formula & RDB & $\begin{array}{l}{[\mathbf{M}-\mathbf{H}]^{-}(m / z)} \\
\text { Found }\end{array}$ & $\begin{array}{l}{[\mathbf{M}-\mathbf{H}]^{-}(m / z)} \\
\quad \text { calcd. }\end{array}$ & ppm & MS/MS $(m / z)$ & Tentative Assignment \\
\hline 17 & 10.024 & $\mathrm{C}_{27} \mathrm{H}_{30} \mathrm{O}_{15}$ & 13.0 & 593.1507 & 593.1512 & -0.8 & 593.1536 (100), 285.0395, 284.0314, 255.0287 & Kaempferol-3-O-hexosyldeoxyhexoside \\
\hline 18 & 10.024 & $\mathrm{C}_{28} \mathrm{H}_{32} \mathrm{O}_{17}$ & 13.0 & 639.1578 & 639.1567 & 1.8 & $\begin{array}{c}\text { 639.1594, } 315.0507(100), 300.0267,314.0426 \\
299.0187,271.0237,255.0287\end{array}$ & Isorhamnetin-3-O-dihexoside \\
\hline 19 & 10.885 & $\mathrm{C}_{27} \mathrm{H}_{30} \mathrm{O}_{15}$ & 13.0 & 593.1527 & 593.1512 & 2.5 & $\begin{array}{c}593.1444,285.0403,284.0323 \text { (100), } 255.0298 \\
227.0335\end{array}$ & Kaempferol-3-O-rutinoside \\
\hline 20 & 10.338 & $\mathrm{C}_{21} \mathrm{H}_{20} \mathrm{O}_{11}$ & 12.0 & 447.0927 & 447.0933 & -1.3 & $\begin{array}{c}447.0925,285.0388,284.0316(100), 255.0283 \\
227.0333\end{array}$ & Keampferol-3-O-hexoside (1) \\
\hline 21 & 10.974 & $\mathrm{C}_{21} \mathrm{H}_{20} \mathrm{O}_{11}$ & 12.0 & 447.0930 & 447.0933 & -0.6 & $\begin{array}{c}447.0915,285.0391,284.0314(100), 255.0280 \\
227.0334\end{array}$ & Keampferol-3-O-hexoside (2) \\
\hline 22 & 10.424 & $\mathrm{C}_{23} \mathrm{H}_{22} \mathrm{O}_{13}$ & 13.0 & 505.0997 & 505.0988 & 1.9 & $\begin{array}{c}\text { 505.1005, 463.0879, 301.0351, 300. } 0273(100) \\
271.0253,255.0287 ; 243.0315 ; 151.0027\end{array}$ & Quercetin-3-O-acetylhexoside (1) \\
\hline 23 & 10.615 & $\mathrm{C}_{25} \mathrm{H}_{24} \mathrm{O}_{12}$ & 14.0 & 515.1197 & 515.1195 & 0.4 & $\begin{array}{c}353.0878 \\
191.0561(100), 179.0346,135.0450\end{array}$ & Dicaffeoyl quinic acid \\
\hline 24 & 10.872 & $\mathrm{C}_{27} \mathrm{H}_{30} \mathrm{O}_{15}$ & 13.0 & 593.1515 & 593.1512 & 0.5 & 593.1436, 285.0404 (100), 284.0324, 255.0290 & Kaempferol-7-O-rutinoside \\
\hline 26 & 11.013 & $\mathrm{C}_{28} \mathrm{H}_{32} \mathrm{O}_{16}$ & 13.0 & 623.1634 & 623.1618 & 2.6 & $\begin{array}{c}623.1645,315.0512 \\
314.0437(100), 300.0275,299.0199,243.0300\end{array}$ & $\begin{array}{c}\text { Isorhamnetin-3-O- } \\
\text { hexosyldeoxyhexoside (1) }\end{array}$ \\
\hline 27 & 11.247 & $\mathrm{C}_{22} \mathrm{H}_{22} \mathrm{O}_{12}$ & 12.0 & 477.1043 & 477.1029 & 0.9 & $\begin{array}{c}477.1037,315.0497 \\
314.0422(100), 300.0258,299.0181,285.0386 \\
271.0234,243.0287,242.0207\end{array}$ & Isorhamnetin-3-O-hexoside (1) \\
\hline 28 & 11.366 & $\mathrm{C}_{28} \mathrm{H}_{32} \mathrm{O}_{16}$ & 13.0 & 623.1629 & 623.1618 & 1.8 & $\begin{array}{c}623.1656,315.0514(100) \\
314.0436,299.0200,271.0253,255.0297 \\
243.0298\end{array}$ & $\begin{array}{c}\text { Isorhamnetin-3-O- } \\
\text { hexosyldeoxyhexoside (2) }\end{array}$ \\
\hline 29 & 11.442 & $\mathrm{C}_{22} \mathrm{H}_{22} \mathrm{O}_{12}$ & 12.0 & 477.1043 & 477.1029 & 0.9 & $\begin{array}{c}477.1053,315.0501 \\
314.0430(100), 299.0193,285.0396,271.0244 \\
243.0291,242.0217\end{array}$ & Isorhamnetin-3-O-hexoside (2) \\
\hline
\end{tabular}


Table 1. Cont.

\begin{tabular}{|c|c|c|c|c|c|c|c|c|}
\hline Peak $n^{\circ}$ & $t_{R}(\min )$ & Formula & RDB & $\begin{array}{l}{[\mathbf{M}-\mathbf{H}]^{-}(m / z)} \\
\text { Found }\end{array}$ & $\begin{array}{l}{[\mathrm{M}-\mathrm{H}]^{-}(\mathrm{m} / z)} \\
\quad \text { calcd. }\end{array}$ & ppm & MS/MS $(m / z)$ & Tentative Assignment \\
\hline 30 & 11.617 & $\mathrm{C}_{33} \mathrm{H}_{28} \mathrm{O}_{17}$ & 20 & 695.1270 & 695.1254 & 2.3 & $\begin{array}{c}695.1256,533.0958,371.0620,209.0299(100) \\
191.0186\end{array}$ & Tricaffeoyl citric acid (1) \\
\hline 31 & 11.833 & $\mathrm{C}_{33} \mathrm{H}_{28} \mathrm{O}_{17}$ & 20 & 695.1267 & 695.1254 & 1.9 & $\begin{array}{c}\text { 695.1305, 533.0978, 371.0633, 353.0513, } \\
209.0303(100), 101.0191,85.0293\end{array}$ & Tricaffeoyl citric acid (2) \\
\hline 32 & 11.963 & $\mathrm{C}_{24} \mathrm{H}_{24} \mathrm{O}_{13}$ & 13.0 & 519.1155 & 519.1148 & 2.1 & $\begin{array}{c}519.1174,315.0507,314.0432(100), 300.0279 \\
\text { 299.0192, 285.0397, } 271.0241\end{array}$ & Isorhamnetin-3-O-acetylhexoxide \\
\hline 33 & 12.026 & $\mathrm{C}_{33} \mathrm{H}_{28} \mathrm{O}_{17}$ & 20 & 695.1268 & 695.1254 & 2.1 & $\begin{array}{c}\text { 695.1284, 533.0977, 371.0616, 353.0487, } \\
\text { 209.0297 (100), 191.0298 }\end{array}$ & Tricaffeoyl citric acid (3) \\
\hline 34 & 12.164 & $\mathrm{C}_{24} \mathrm{H}_{24} \mathrm{O}_{13}$ & 13.0 & 519.1163 & 519.1148 & 3.6 & $\begin{array}{c}519.1161,315.0499,314.0423(100), 300.0264 \\
299.0192,285.0394,271.0237\end{array}$ & Isorhamnetin-3-O-acetylhexoxide \\
\hline 35 & 13.538 & $\mathrm{C}_{15} \mathrm{H}_{10} \mathrm{O}_{7}$ & 11.0 & 301.0354 & 301.0354 & 0.1 & $\begin{array}{c}301.0349,273.0401,245.0472,178.9986 \\
151.0037(100), 107.0136\end{array}$ & Quercetin \\
\hline 36 & 15.960 & $\mathrm{C}_{54} \mathrm{H}_{88} \mathrm{O}_{24}$ & 11.0 & $\begin{array}{c}{\left[\mathrm{M}+\mathrm{HCOO}^{-}\right]^{-}} \\
1165.5691 \\
{\left[\mathrm{M}+\mathrm{Cl}^{-}\right]^{-}} \\
1155.5410\end{array}$ & 1119.5593 & n.c. & $\begin{array}{c}957.5162,837.4726,795.4604(100), 777.4502 \\
733.4599,633.4058,615.3949,505.3716 \\
471.3505,407.3335,161.0449,119.0346 \\
113.0243\end{array}$ & $\begin{array}{l}\text { 3-O-trihexosyl 28-O-echinocystic acid } \\
\text { hexosyl ester }\end{array}$ \\
\hline 37 & 16.229 & $\mathrm{C}_{48} \mathrm{H}_{76} \mathrm{O}_{20}$ & 11.0 & 971.4901 & 971.4857 & 4.5 & $\begin{array}{c}971.4929,851.4468,809.4365(100), 747.4366 \\
647.3833,585.3834,513.3617,471.3478 \\
409.3477,407.3328,157.0152,119.0344 \\
113.0240\end{array}$ & $\begin{array}{l}\text { 3-O-(hexosyl)hexuronidyl } \\
\text { 28-O-echinocystic acid hexosyl ester }\end{array}$ \\
\hline 38 & 16.603 & $\mathrm{C}_{48} \mathrm{H}_{78} \mathrm{O}_{19}$ & 10.0 & $\begin{array}{c}{\left[\mathrm{M}+\mathrm{HCOO}^{-}\right]^{-}} \\
1003.5116\end{array}$ & 957.5065 & n.c. & $\begin{array}{c}795.4572(100), 733.4632,633.4036,615.3947 \\
471.3478,161.0433,101.0245\end{array}$ & $\begin{array}{c}\text { 3-O-dihexosyl 28-O-echinocystic acid } \\
\text { hexosyl ester }\end{array}$ \\
\hline 39 & 16.758 & $\mathrm{C}_{42} \mathrm{H}_{66} \mathrm{O}_{15}$ & 10.0 & 809.4365 & 809.4388 & 4.5 & $\begin{array}{c}\text { 809.4373, 689.3982, 647.3858, 585.3823, } \\
539.3798,471.3512,425.3427,407.3340(100) \\
391.3033,245.1536,113.0244\end{array}$ & $\begin{array}{l}\text { 3-O-hexuronidyl 28-O-hexoxyl } \\
\text { echinocystic acid }\end{array}$ \\
\hline 40 & 17.088 & $\mathrm{C}_{42} \mathrm{H}_{66} \mathrm{O}_{15}$ & 10.0 & 809.4369 & 809.4388 & 3.8 & $\begin{array}{c}809.4419,647.3859,603.3941,485.3646 \\
471.3508(100), 469.3355,453.3399,439.3254 \\
393.3168,113.0243\end{array}$ & $\begin{array}{c}\text { 3-O-hexuronidyl } \\
\text { 28-O-mesembryanthemoidigenic } \\
\text { hexosyl ester }\end{array}$ \\
\hline 41 & 17.939 & $\mathrm{C}_{48} \mathrm{H}_{74} \mathrm{O}_{45}$ & 12.0 & 953.4785 & 953.4752 & 3.6 & $\begin{array}{c}\text { 809.4382, } 689.3939,647.3846(100), 585.3841 \\
539.3767,471.3505,407.3328,409.3488 \\
391.3006,113.0242\end{array}$ & $\begin{array}{c}\text { 3-O- } \\
\text { (hydroxymethylglutarylhexosyl)hexuronidyl } \\
\text { echinocystic acid }\end{array}$ \\
\hline
\end{tabular}


Table 1. Cont.

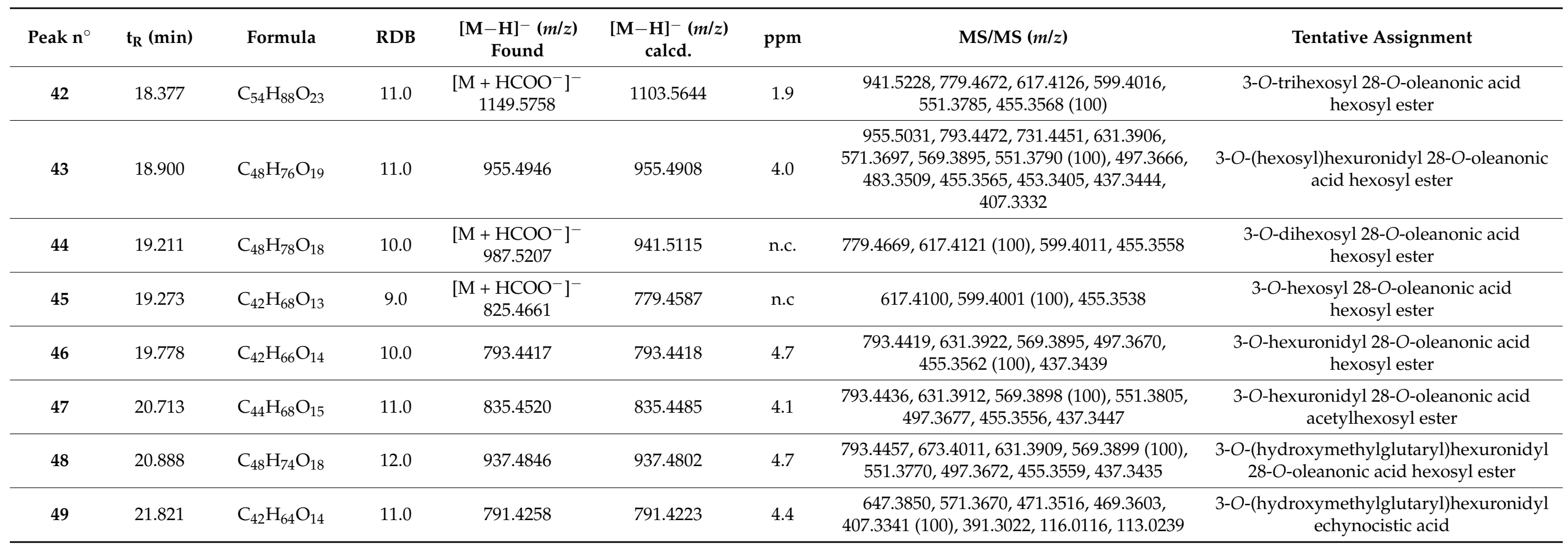




\subsubsection{Hydroxycinnamic Acids Derivatives}

Compounds 6-9, 23, 30, 31, and 33 are hydroxycinnamoyl derivatives. In particular, compound 6 with the $[\mathrm{M}-\mathrm{H}]^{-}$ion at $m / z 341.0880$ was tentatively identified as caffeoyl hexose based on its TOF-MS/MS spectrum, which displayed the ion at $m / z 251.0570$, according to the hexose cross-ring cleavage with the neutral loss of $90 \mathrm{Da}$, and the ion at $m / z 179.0354$, due to the loss of $162.05 \mathrm{Da}$ (hexose- $\mathrm{H}_{2} \mathrm{O}$ ). The dehydration of the ion at $\mathrm{m} / \mathrm{z} 179.0354$ provided the base peak of the other characteristic caffeic acid ion at $m / z 161.0252$. Otherwise, the caffeate decarboxylation produced the fragment ion at $m / z 135.0456$. This compound was previously identified in the aerial part of C. arvensis L. [39]. Compounds 7, 8, 9, and 23 belong to the chlorogenic acid family. The TOF-MS/MS spectra of the first two metabolites, with relative deprotonated molecular ions at $m / z 353.0877$ and 353.0876, were in agreement with two geometric isomers of 5-O-caffeoylquinic acid $\left(\mathrm{C}_{16} \mathrm{H}_{18} \mathrm{O}_{9}\right)$. In fact, TOF-MS/MS fragment ions were in the quinate, which appeared as the base peak at $m / z 191.0561$ and 191.0566, respectively [49]. Compound 9 with the $[\mathrm{M}-\mathrm{H}]^{-}$ion at $m / z 367.1038$ was likely 5-O-feruloyl quinic acid. To strengthen this hypothesis, the TOFMS/MS fragment ions at $m / z 193.0513$ (ferulate) and 191.0560 were observed. The compound 23 with $[\mathrm{M}-\mathrm{H}]^{-}$ion at $m / z 515.1197$ and fragment ions at $m / z$ 353.0878, 191.0561 (base peak), and 179.0346 was tentatively identified as 3,5-di-O-caffeoylquinic acid, which was reported as constituent of $C$. officinalis inflorescences, as well as of $C$. arvensis aerial parts [39]. Compounds 30, 31, and 33, with relative [M-H] ${ }^{-}$ion at $m / z$ 695.1270, 695.1267, and 695.1268, were tentatively identified as tricaffeoylcitric acid isomers. TOF-MS/MS experiments, whose spectra are in Figure S1, displayed the sequential loss of three dehydrated caffeoyl moieties to generate the fragment ions at $m / z$ 533.09, 371.06, and 209.02. The fragment ion at $m / z 371.06$ underwent further $\mathrm{H}_{2} \mathrm{O}$ loss to provide the ion at $m / z 353.05$, which, losing a dehydrated caffeic acid, formed the citrate ion at $m / z$ 191.01. Although these caffeic acid derivatives were not previously isolated in the Calendula genus, they are already known for some Asteraceae (i.e., in roots of Smallanthus sonchifolius (Poepp.) H.Rob [50] and in aerial parts of Galinsoga parviflora Cav. [51]), and displayed antiglycative activity, inhibiting the formation of AGEs (Advanced Glycation End-products) [52].

\subsubsection{Flavonoids}

A total of 22 compounds were found to be flavonol glycosides. In particular, compounds 10-16 are quercetin glycosides (Figure S2). Compound 10, with the $[\mathrm{M}-\mathrm{H}]^{-}$ion at $\mathrm{m} / z 625.1414$, was putatively a quercetin-3-O-dihexoside. Following the neutral loss of $324 \mathrm{Da}$ from the $[\mathrm{M}-\mathrm{H}]^{-}$ion, the [aglycone-H] $]^{-}$ion at $\mathrm{m} / \mathrm{z} 301.0346$ and its abundant radical at $m / z 300.0269$ were provided in accordance with the glycosylation site at C-3 carbon of the flavonol. Compounds 11 and 14, with relative $[\mathrm{M}-\mathrm{H}]^{-}$ion at $m / z 595.1301$ and 595.1309, were likely two isomers of quercetin-3-O-hexosylpentoside, giving rise to the neutral loss of $294.09(162.05+132.04)$ Da. To confirm the presence of a pentosyl unit, a fragment ion at $m / z 463.0916(<5 \%)$ was detectable in the TOF-MS/MS spectrum of compound 14. Quercetin-3-O-hexosylpentoside was recently tentatively identified in Calendula officinalis flowers [53]. Compounds 12 and 15, with the $[\mathrm{M}-\mathrm{H}]^{-}$ion at $m / z 609.147$, were two isomers of quercetin hexosyldeoxyhexoside. Both the $[\mathrm{M}-\mathrm{H}]^{-}$ ions underwent the loss of $308.11 \mathrm{Da}$ to achieve the [aglycone- $\mathrm{H}]^{-}$and the [aglycone-H] ${ }^{\bullet-}$ ions, whereas the radical aglycone ion was favorably formed for the compound 15. The TOF-MS/MS spectrum of this latter was superimposable with that of rutin [54]. Compound 12, likely quercetin 3-O-neohesperidoside (also known as calendoflavobioside), was already identified in C. officinalis, along with other rhamnosyl glucosides. Indeed, calendosides I-II, isolated from $C$. officinalis, were consistent in quercetin-3-O- $\left(4^{\prime \prime}-\alpha-\mathrm{L}-\right.$ rhamnopyranosyl- $\beta$-D-glucopyranoside and quercetin-3- $O-\left(3^{\prime \prime}-\alpha\right.$-L-rhamnopyranosyl- $\beta$ D-glucopyranoside [55,56]. Compounds 13 and 16, with $[\mathrm{M}-\mathrm{H}]^{-}$ion at $\mathrm{m} / \mathrm{z} 463.0882$ and $m / z$ 463.0883, respectively, were quercetin-3-O-hexoside isomers, which underwent 162.05 Da loss in TOF-MS/MS experiment. The relative abundance of the [aglycone-H] ${ }^{\bullet-}$ and [aglycone-H] ${ }^{-}$was in a 3:1 ratio for compound 13, whereas it was in a 3:2 ratio for com- 
pound 16. The latter was likely quercetin-3-O- $\beta$-glucoside (isoquercitrin), previously identified in C. arvensis aerial parts [57], while compound $\mathbf{1 3}$ was hyperin [58], which was found to exert an intracellular antioxidant activity in hepatoblastoma HepG2 cell line higher than that isoquercitrin, because of the presence of specific protein receptors for galactosides [59]. Compounds 22 and 25, with deprotonated molecular ions at $m / z 505.0997$ and 505.0998, respectively, were tentatively identified as acetyl derivative of quercetin-3-O-hexoside. Literature evidence demonstrated the isolation of derivative with 3-O-(2"-acetyl)-glucoside and 3-O-(6"-acetyl)-glucoside saccharidic moieties from C. officinalis flower [53]. These compounds were distinguishable based on the relative neutral losses from the $[\mathrm{M}-\mathrm{H}]^{-}$ ion, which accounted to 42 Da for compound 22 and $60 \mathrm{Da}$ (more favourable for the 2"acetylderivative) for compound 25. Quercetin was compound 35, which displayed the $[\mathrm{M}-\mathrm{H}]^{-}$ion at $m / z$ 301.0354, and the diagnostic TOF-MS/MS signals at $m / z 273.0401$ and 245.0472. The ion at $m / z 178.9986$ underwent CO loss to give the ion at $m / z 151.0037$. Further $\mathrm{CO}_{2}$ loss furnished the ion at $m / z$ 107.0136.

Compounds 17, 19, 20, 21, and 24 were identified as kaempferol glycosides. Even though these compounds are poorly reported in the literature about Calendula spp. [60], the neutral loss of $324 \mathrm{Da}$ in the TOF-MS/MS spectra of compounds 17 and 19 were in agreement with kaempferol-3-O-hexosyldeoxyhexoside isomers, whereas the loss of 162.05 Da suggested that compounds $\mathbf{2 0}$ and $\mathbf{2 1}$ were two hexosyl derivatives, of which kaempferol3-O-glucoside was already reported in C. officinalis [61]. The TOF-MS/MS of compound 24, with the base peak at $m / z 285.0404$, was in line with kaempferol-7-O-hexosyldeoxyhexoside. Isorhamnetin is the aglycone in compounds $\mathbf{1 8}$, and $\mathbf{2 6 - 2 9}$. Several isorhamnetin glycosides were previously isolated in C. officinalis, of which calendoflavoside and narcissin, herein identified in compounds $\mathbf{2 6}$ and $\mathbf{2 8}$, were found abundant [54]. The TOF-MS/MS spectrum of the compound 18, with the $[\mathrm{M}-\mathrm{H}]^{-}$ion at $m / z$ 639.1578, was in agreement with the presence of a dihexosyl isorhamnetin. Compounds 27 and 29 were tentatively identified as isomers of isorhamentin-3-O-hexoside [54], whereas compounds $\mathbf{3 2}$ and $\mathbf{3 4}$ with the $[\mathrm{M}-\mathrm{H}]^{-}$ions at $m / z 519.1155$ and 519.1163 , respectively, were tentatively identified as isorhamnetin acetylhexoside isomers. Although these metabolites were first identified in $C$. arvensis, isorhamnetin-3-O-(6"-acetyl-)- $\beta$-D-glucopyranoside was recently isolated among anti-acetylcholinesterase inhibitors of $C$. officinalis florets [62].

\subsubsection{Triterpene Saponins}

A great part of the identified metabolites were triterpene saponins, already widely known as bioactive constituents of the Calendula genus. These compounds are known for their anti-inflammatory, antiallergic, antiulcer, immunomodulatory, cytotoxic, antimutagen, hepatoprotective, antihyperglycemic, hemolytic, antimicrobial and trypanocidal activities. It was reported that $C$. officinalis biosynthesizes oleanane saponins in all its organs, distinguishable in two series of compounds, namely the 3-O-monoglucoside oleanolic acid and 3-O-monoglucuronide oleanolic acid derivatives [63].

Recently, new bisdesmoside triterpene saponins, calendustellatosides A-E, have been described in C. stellata. The most representative aglycones are oleanolic, echinocystic, morolic, and mesembrianthemoidigenic acids, whereas saccharidic units are localized to C-3 and C-28 carbons [64]. At the beginning of nineties, the antipyretic and anti-inflammatory efficacy of $C$. arvensis dictated the phytochemical study of plants, resulting in the identification of these components [57], some of whom are named arvensosides [65]. Indeed, the extracts prepared from this plant were traditionally used as disinfectants, antispasmodics, diuretics, and for its diaphoretic and sedative properties [35]. To the best of our knowledge, no data about mass spectrometric behaviour of these compounds are reported and the study of their fragmentation pattern represents an excellent tool for their efficient and fast recognition in C. arvensis-based products. The compounds tentatively identified are reported in Figure S3.

Compound 36 was tentatively identified as 3-O-trihexosyl 28-O-echinocystic acid hexosyl ester. This metabolite was detected in the TOF-MS spectrum as formic acid adduct 
$\left[\mathrm{M}+\mathrm{HCOO}^{-}\right.$at $m / z$ 1165.5691. This first evidence suggested the lack of a primarily acid site. The TOF-MS/MS spectrum highlighted the neutral loss of $162.05 \mathrm{Da}$, attributed to the (hexose- $\mathrm{H}_{2} \mathrm{O}$ ) residue, to form the fragment ion at $m / z 957.5162$ by ester bond cleavage at C-28 (Figure S4). A cross ring cleavage of saccharidic moiety and the loss of 120 Da supplied the ion at $m / z 837.4726$, suggesting a 1-2 bond between the units [66], whereas, through the further loss of $162.05 \mathrm{Da}$, the ion at $m / z 795.4604$ was generated. The latter, attributed to a hexosyl-saponin, underwent $\mathrm{H}_{2} \mathrm{O}$ loss to achieve the ion at $m / z 777.4502$, and a concerted loss of $(44+18)$ Da to provide the ion at $m / z$ 633.4058, which, through further $\mathrm{H}_{2} \mathrm{O}$ loss, gave the ion at $m / z 615.3949$, while the loss of 162.05 Da generated the fragment ion at $m / z 471.3505$, due to the deprotonated aglycone, tentatively identified as echinocystic acid. The $\mathrm{H}_{2} \mathrm{O}$ and $\mathrm{HCOOH}$ loss from the [aglycone- $\left.\mathrm{H}\right]^{-}$ion favoured the ion at $m / z 407.3335$ formation. Based on this evidence, calendulostellaside A (3-O- $\beta$-D-glucopyranosyl- $(1 \rightarrow 2)-$ $[\beta$-D-galactopyranosyl- $(1 \rightarrow 3)]-\beta$-D-glucopyranosyl echinocystic $28-O-\beta$-D glucopyranosyl ester), previously isolated in C. stellata Cav., was tentatively identified. This compound was reported to be inactive $\left(\mathrm{IC}_{50}>50 \mu \mathrm{M}\right)$ vs. fibrosarcoma (HT1080) and human lung cancer (A549) cell lines, and able to exert a low antibacterial inhibition of Enterococcus faecalis, Escherichia coli, Pseudomonas aeruginosa, and Staphylococcus epidermidis [64].

Compound 37, with a deprotonated molecular ion at $m / z 971.4901\left(\mathrm{C}_{48} \mathrm{H}_{76} \mathrm{O}_{20}\right)$, was tentatively identified as 3-O-(hexosyl)hexuronidyl 28-O-echinocystic hexosyl ester or calendasaponin B, previously isolated in flower of C. officinalis [67]. In fact, the $[\mathrm{M}-\mathrm{H}]^{-}$ ion, following the neutral loss of 120.04 and $162.05 \mathrm{Da}$, formed the fragment ions at $m / z$ 851.4468, and 809.4365. The latter provided an ion at $m / z 747.4366$ through the neutral loss of $(44+18) \mathrm{Da}$, which could likely take place on the hexuronyl unit. Confirming this hypothesis, a further loss of $162.05 \mathrm{Da}$ was detected and the ion at $\mathrm{m} / \mathrm{z} 585.3834$ was formed. The subsequent loss of $114.03 \mathrm{Da}$ gave echinocystate, which lost a further $64 \mathrm{Da}$, furnishing the ion at $m / z 407.3328$ (Figure S5).

The TOF-MS spectrum of compound 38 displayed the $\left[\mathrm{M}+\mathrm{HCOO}^{-}\right]^{-}$ion at $m / z 1003.5116$, while the TOF-MS/MS data were consistent with 3-O-dihexoxyl 28-O-echinocystic hexosyl ester (e.g., calendustellaside B) [64]. In fact, an abundant fragment ion at $m / z$ 795.4572, was likely through the cleavage of the aglycone ester bond. This ion underwent the neutral loss of 162.05 Da to give the fragment ion at $m / z$ 633.4036, which, with further water loss, generated the ion at $m / z$ 615.3947; or, through the loss of $162.05 \mathrm{Da}$, provided the ion at $m / z$ 471.3478, which consisted of the echinocystate (Figure S6). Compound 39, with the deprotonated molecular ion at $m / z$ 809.4365, was tentatively identified as 3-O-hexuronidyl 28-hexoxyl echinocystic acid. The TOF-MS/MS experiment emphasized the occurrence of ions deriving through 120.04 and 162.05 Da neutral loss at $m / z 689.3982$ and 647.3858, respectively. The hexuronidyl moiety favored the concerted loss of $(44+18)$ Da to achieve the ion at $m / z 585.3823$, and the further loss of $114.03 \mathrm{Da}$ to obtain the deprotonated aglycone ion. The ion at $m / z 585.3823$ could also lose 46 Da to give the ion at $m / z 539.3798$ (Figure S7). The compound was tentatively identified as achantopanaxoside E, previously isolated from C. stellata [64], and reported to exert mild inhibition of pancreatic lipase [68]. Compound 40 was tentatively identified as 3-O-hexuronidyl 28-O-mesembriantemoidigenic hexosyl ester (Figure S8). The ion $[\mathrm{M}-\mathrm{H}]^{-}$at $m / z 809.4369$ agreed with a constitutional isomer of a previous compound, from which it likely differs in aglycone. The loss of 162.05 Da in the TOF-MS/MS spectrum gave the ion at $m / z 647.3859$, and the following loss of $62 \mathrm{Da}$, favourably from glucuronate residue, generated the ion at $m / z 585.3841$. The latter, through the loss of $114.03 \mathrm{Da}$, provided the deprotonated aglycone at $m / z 471.3508$ as base peak. A decarboxylation of the ion at $m / z 647.3859$ gave the fragment ion at $m / z 603.3941$. The neutral loss of $32 \mathrm{Da}$ was likely due to the loss of the hydroxymethyl functional group located in C-29 or C-30 carbons to provide the ion at $m / z$ 439.3254 [69]. Compound 41 was putatively 3-O-(hydroxymethylglutarylhexosyl)hexuronidyl echinocystic acid, previously identified as the antiviral glycoside 5 [57]. The TOF-MS/MS spectrum displayed the ion at $m / z 809.4382$, due to the loss of hydroxymethylglutaryl moiety ( $-144 \mathrm{Da}$ ). The presence of a hexose unit in C-28 carbon was suggested by the neutral losses of 120.04 and 162.05 Da to 
form the ions at $m / z 689.3939$ and 647.3846, respectively (Figure S9). The decarboxylation and dehydration of the hexuronyl unit $(-(44+18) \mathrm{Da})$ provided the ion at $m / z 585.3841$, whereas the following loss of 46 Da gave the ion at $m / z$ 539.3767. The [aglycone- $\mathrm{H}]^{-}$ ion at $m / z 471.3505$ was through the hexuronyl moiety loss $(-176.03 \mathrm{Da})$ from the ion at $m / z$ 647.3846, and/or the loss of 114.03 Da from the ion at $m / z 585.3841$. The metabolite was putatively identified for the first time in the Calendula genus. Compound $\mathbf{4 2}$ was likely 3-O-trihexosyl 28-O-oleanonic acid hexosyl ester. The $\left[\mathrm{M}+\mathrm{HCOO}^{-}\right]^{-}$ion at $m / z 1149.5758$ provided, in the TOF-MS/MS spectrum, the fragment ion at $m / z 941.5228$, in agreement with the ester bond cleavage and the hexosyl moiety loss (-162.05 Da) at C-28 carbon, whereas the further loss of two hexoses provided the ions at $m / z 779.4672$ and 617.4126. The latter ion lost $\mathrm{H}_{2} \mathrm{O}$ to give the ion at $m / z 599.4016$ (Figure S10). Compound 43 was tentatively 3-O-(dihexoxyl)hexuronidyl 28-O-oleanonic acid hexosyl ester or calenduloside $\mathrm{H}$ (also known as saponoside $\mathrm{C}$ ), from the flowers of Calendula officinalis and aerial parts of C. arvensis [67]. The TOF-MS/MS spectrum displayed the deprotonated molecular ion at $m / z$ 955.5031, from which the ion at $m / z$ 793.4472, through hexosyl moiety loss, was formed, and further underwent 62 Da loss to provide the ion at $m / z$ 731.4451, or hexosyl moiety loss, to obtain the weak ion at $m / z$ 631.3906. Analogously, the loss of $162.05 \mathrm{Da}$ from the ion at $m / z 731.4451$ formed that at $m / z 569.3895$, which could provide the ions at $m / z 551.3783$ and 455.3557 , by $\mathrm{H}_{2} \mathrm{O}$ and $96 \mathrm{Da}$ losses, respectively (Figure S11). The compound 44 was tentatively 3-O-dihexosyl 28-O-oleanonic acid hexosyl ester, likely arvensoside A [70]. The $\left[\mathrm{M}+\mathrm{HCOO}^{-}\right]^{-}$at $m / z 987.5207$ lost $162.05 \mathrm{Da}$ to give the ion at $m / z$ 779.4669, which, for further loss of $162 \mathrm{Da}$, gave the ion at $m / z$ 617.4121. Further $\mathrm{H}_{2} \mathrm{O}$ loss gave the ion at $m / z$ 599.4011, whereas the [aglycone- $\mathrm{H}]^{-}$ion was formed as base peak after the loss of 162.05 Da (Figure S12).

The $\left[\mathrm{M}+\mathrm{HCOO}^{-}\right]^{-}$for the compound 45 at $m / z 825.4661$ was in accordance with the 3-O-hexosyl 28-O-oleanonic acid hexosyl ester. The TOF-MS /MS spectrum displayed the product ion at $m / z 617.4099$ (formed by the loss of 162.05 Da from the undetectable deprotonated molecular ion, with a theoretical $\mathrm{m} / \mathrm{z}$ at 779.4587), which gave the fragment ion at $m / z 455.3564$ for further loss of $162.05 \mathrm{Da}$. The loss of $180 \mathrm{Da}$ from the [M-H] ${ }^{-}$ putative ion provided the base peak at $m / z$ 599.3986. Even though the metabolite shares its molecular formula with arvensoside B, the absence of information about the deprotonated molecular ion allowed us to hypothesize a constitutional isomer of the compound previously isolated, glycosylated at C-3 and C-28 carbons (Figure S13). Accordingly, silphioside B (3-O- $\beta$-D-glucopyranosyl oleanolic acid 28-O- $\beta$-D-glucopyranosyl ester) was isolated from C. stellata [64]. Compound 46 was tentatively identified as 3-O-hexuronidyl oleanonic acid hexosyl ester. The TOF-MS/MS spectrum displayed the ion at $m / z 631.3922$, formed for loss of hexose unit $(-162.05 \mathrm{Da})$ from the deprotonated molecular ion. The decarboxylation and dehydration of the hexuronyl unit $(44+18) \mathrm{Da}$ formed the fragment ion at $m / z 569.3895$, which could lose $72 \mathrm{Da}$ to provide the ion at $m / z 497.3677$, or $114.03 \mathrm{Da}$ to form the ion at $m / z 455.3562$. The latter could be also obtained by the neutral loss of $176.03 \mathrm{Da}$ from the ion at $\mathrm{m} / z$ 631.3922 (Figure S14). The compound is likely calenduloside F, previously isolated from the root of $C$. officinalis [71]. Compound 47, with the deprotonated molecular ion at $m / z$ 835.4525, was tentatively identified as 3-O-hexuronidyl 28-O-oleanonic acid acetylhexosyl ester. The TOF-MS/MS spectrum displayed the product ion at $m / z$ 793.4436, generated from the loss of an acetylhexose- $\mathrm{H}_{2} \mathrm{O}(-204.06 \mathrm{Da})$ unit. The fragment ion at $m / z 569.3898$ was by decarboxylation and dehydration of hexuronyl moiety $(44+18)$ Da. The subsequential loss of $72 \mathrm{Da}$ was observed for cross-ring cleavage to provide the fragment ion at $m / z$ 497.3677, which in turn generated, by loss of $42 \mathrm{Da}$, the fragment ion at $m / z 455.3556$ (Figure S15). This metabolite was identified for the first time in Calendula genus. Compound 48 was tentatively identified as 3-O(hydroxymethylglutaryl)hexuronidyl 28-O-oleanonic acid hexosyl ester. Its TOF-MS/MS spectrum showed the ion at $m / z$ 793.4457, generated through the loss of the hydroxymethylglutaryl unit $(-144 \mathrm{Da})$ from the deprotonated molecular ion, and the ion at $m / z 631.3909$, due to the further 162.05 Da neutral loss. The fragment ion at $m / z 569.3899$ was provided 
by decarboxylation and dehydration of the hexuronyl unit. Finally, in the TOF-MS/MS spectrum, the deprotonated aglycone moiety at $m / z$ 455.3559, putatively identified as oleanolic acid, was detectable, together with the ion at $m / z$ 437.3425, due to further water loss (Figure S16). The compound was previously isolated in Calendula arvensis as arvensoside C. The compound 49 with the deprotonated molecular ion at $m / z 791.4258$ was putatively identified as 3-O-(hydroxymethylglutaryl)hexuronidyl echynocistic acid. The TOF-MS/MS spectrum highlighted the fragment ion at $m / z$ 647.3850, formed by the loss of the hydroxymethylglutaryl unit $(-144 \mathrm{Da})$. The presence of a glucuronate moiety was suggested by the further neutral loss of $176.03 \mathrm{Da}$, which provided the ion at $\mathrm{m} / z 471.3516$ and $m / z$ 407.3341 (Figure S17).

3.1.4. Guidelines for the Straightforward Identification of Triterpene Saponins by HR-MS/MS Tools

The TOF-MS and TOF-MS/MS data allow us to describe some guidelines that favour the rapid identification of this class of compounds in complex mixtures. In fact, it is observed that when the compound is glycosylated, both in the alcoholic function in C-3 and in the carboxylic function in C-28, only the adduct with formic acid is detectable in the TOF-MS spectrum, and, more likely, the first fragment ion observed in the TOF-MS/MS spectra is the result of the loss of a dehydrated hexose sugar from the undetected molecular deprotonated ion. The latter was well distinguishable in the TOF-MS spectra of compounds in which an oxidized sugar occurs, or in compounds whose C-28 carbon was not esterified. Compounds with hexuronate, beyond neutral losses of $162.05 \mathrm{Da}$, attributable to [hexose$\left.\mathrm{H}_{2} \mathrm{O}\right]$ residues, displayed the characteristic loss of $176.03 \mathrm{Da}$. Hexuronic acid was also recognized based on the concerted loss of $62 \mathrm{Da}$, which was through decarboxylation $(-44 \mathrm{Da})$ and dehydration $(-18 \mathrm{Da})$, and the loss of a [hexuronic acid- $\left(2 \mathrm{H}_{2} \mathrm{O}+\mathrm{CO}_{2}\right)$ ] moiety. Once an acyl moiety was present (e.g., hydroxymethylglutarate) and linked on a sugar part, it was quickly lost from the deprotonated molecular ion.

\subsubsection{Other Compounds}

Compound 1 was likely malic acid, and compound 2 was quinic acid. In particular, the molecular deprotonated ion at $m / z 133.0140$ for compound $\mathbf{1}$, gave, following the loss of water, the ion at $m / z 115.0036$ as base peak. The TOF-MS spectrum of compound 3 displayed the deprotonated molecular ion at $m / z 341.1108\left(\mathrm{C}_{12} \mathrm{H}_{22} \mathrm{O}_{11}\right)$. The compound was tentatively identified as a dihexose. In the TOF-MS/MS spectrum, the cleavage of $\mathrm{O}$-glycosidic bond and the loss of a hexose unit $(-162.05 \mathrm{Da})$ generated the fragment ion at $m / z$ 179.0562. Confirming its saccharidic nature, it was detected in the fragment ions at $m / z 119.0348$ and at $m / z$ 89.0244, which were formed by the cross-ring cleavage of the saccharidic unit and the corresponding neutral loss of $60 \mathrm{Da}$ and $90 \mathrm{Da}$. This compound was tentatively identified as trehalose, a disaccharide with a glycosidic bond $\alpha\left(1 \rightarrow 1^{\prime}\right)$, already reported in the literature as abundant in C. officinalis [72]. The non-reducing nature of saccharide agreed to the presence of the fragment ion at $m / z$ 179.0562. In fact, non-reducing sugars are distinguished from those reducing (e.g., lactose and maltose) in tandem mass spectrometry by the absence of fragments with a higher $m / z$ ratio, and the fragmentation involves the acetalic bond directly [73]. Trehalose acts, in many organisms, as a source of energy or as a protective agent against the effects of freezing or dehydration. Its physical and/or chemical features allow it to differ from other sugars, and to be favourably engaged as an ingredient for many food, healthcare and, pharmaceutical products [74]. Studies in C. officinalis seedlings observed that the exposition at low temperature strongly increases the content of this osmoprotectant [72]. The TOF-MS spectrum of compound 4, displaying the deprotonated molecular ion at $m / z$ 153.0195, was in accordance with the dihydroxybenzoic acid. In fact, the decarboxylation of the deprotonated molecular ion generated the fragment ion at $m / z 109.0287$ and the radical ion at $m / z$ 108.0214, attributable to the presence of a diphenolic moiety. In this context, protocatechuic acid or 3,4-dihydroxybenzoic acid was previously identified in the methanolic extract of $C$. officinalis flowers [75]. Compound 5, 
with the deprotonated molecular ion at $m / z 285.0619$, was the pentosyl derivative of the previous one. In particular, the loss of 132 Da generated, in the TOF-MS/MS spectrum, the fragment ion at $m / z 153.0190$ and the radical ion at $m / z$ 152.0111. The decarboxylation of the radical ion provided the abundant formation of the ion at $m / z$ 108.0214. This compound was previously identified in a methanolic extract of $C$. arvensis aerial parts [39]. The presence of hydroxybenzoic acid and its derivatives, such as protocatechuic acid hexoside and a syringic acid derivative, was also observed in the subspecies lusitanica (Boiss.) Ohle and algarbiensis (Boiss.) Nyman of C. suffruticosa. [39].

\subsection{Multivariate Analysis}

A multivariate analysis approach was adopted to explore and clarify the qualiquantitative compositive data analysis of each organ. In particular, the principal component analysis (PCA), considering the two principal components (PC) that described $77.6 \%$ of the total variance with $\mathrm{PC} 1$ and $\mathrm{PC} 2$, representing $20.8 \%$ and $56.8 \%$, respectively, highlighted the compositive distinctiveness of florets positioned at the end of the negative score of the PC1 axis. On the contrary, all the other organs grouped in the positive score, even if fruits were at the end of the negative score of PC2 and leaves in the positive one; the root extract was positively correlated with those of stems and bracts (Figure 3).

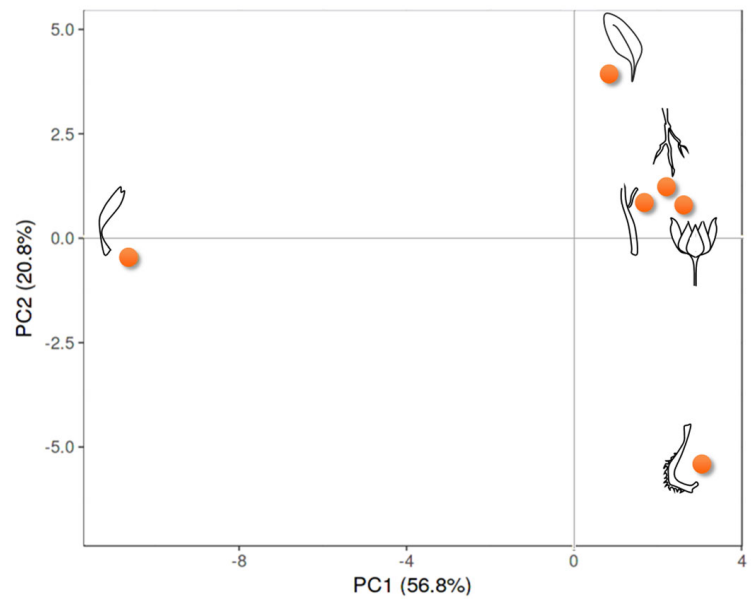

Figure 3. PCA of tentatively identified metabolites in six organs of Calendula arvensis.

The heatmap of the alcoholic extract of $C$. arvensis organs clearly evidenced the cluster segregations of the different quali-quantitative compound compositions in relation to each analysed organ (Figure 4), confirming for the latter the distinctiveness of florets obtained, based on the PCA. Moreover, the other subcluster of organs matched to leaves and stems on the one hand, and roots and bracts on the other. The basis that drives the separation is to achieve homogeneous elements. Considering each individual class of the compounds, it appears clear that fruits and bracts are distinguishable for their higher content of hydroxycinnamic derivative. Florets are rich in flavonoid glycosides and triterpenic saponins. The latter are completely absent in fruits, which are characterized for the greater presence of flavonol acetylglycosides.

\subsection{Antioxidant Activity of Calendula arvensis Alcoholic Extracts}

Data from the in vitro antiradical capability of the alcoholic extracts of the $C$. arvensis organs were preliminarily analysed by cluster analysis, to explore the degree of dissimilarity values between test types and plant organs. An average linkage agglomeration criterion and Jaccard Index as dissimilarity coefficient were applied to each ( 6 organs $\times 5$ concentrations) of the three data matrix of radical scavenging activity (ABTS, PFRAP, and DPPH). 


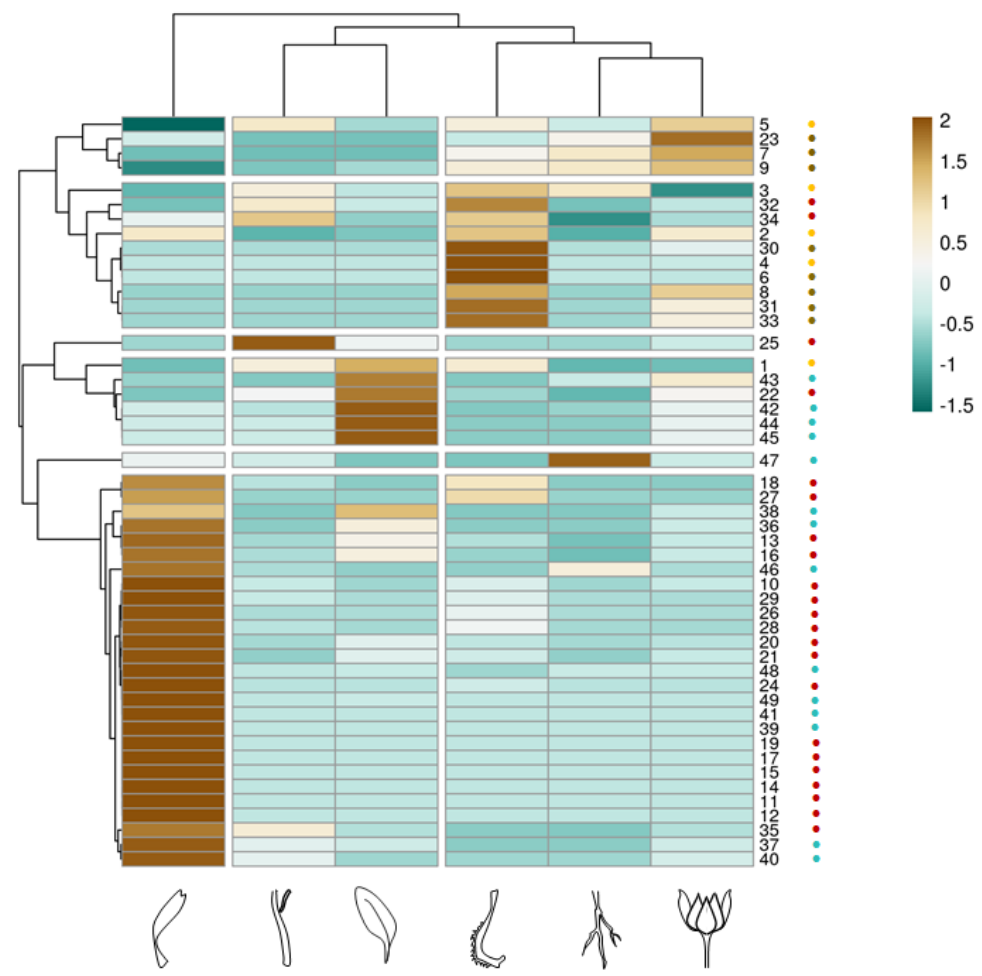

Figure 4. Heatmap of the compounds in the alcoholic extracts from the different organs of Calendula arven-sis: • hydroxycinnamoyl compounds; • flavonoids; • triterpene saponins; • other compounds. Clustering of the investigated samples is displayed above the heatmap. In the ClustVis hierar-chical clustering tool, rows and columns are clustered by means of correlation distance and aver-age linkage.

The obtained dendrograms (Figure 5A) clearly demonstrated different clustering patterns of the organs' alcoholic extract, in relation to the antioxidant test used. The dendrogram obtained for the ABTS data assay highlighted two clusters (Figure 5A1), which have a dissimilarity value of $24 \%$ among them, with the first including bracts, florets, and fruits, while the second grouping was root, stem, and leaf extracts. On the contrary, the cluster analysis for PFRAP assay displayed two main clusters (Figure 5A2), with the first one characterized in turn by two subclusters including bracts, florets, and fruits on one side, and roots and leaves on the other (Figure 5A2 (I.a)), while the second consisted only of stems.

The dendrogram, relating to the results of the DPPH assays, displayed three clusters (Figure 5A3): the first group included bracts and fruit extracts, the second, comprised of roots and flowers, and the third cluster consisted of stem and leaf extracts.

In a second step, the antioxidant activity data were organized and depicted according to the obtained clusters of each dendrogram, respectively (Figure 5B). It can be observed in the ABTS and PFRAP tests that the activity values of bracts, florets, and fruits are grouped in a single cluster, I and Ia respectively, which resulted in the most active and with a similar pattern in relation to concentrations. Stems, leaves, and roots are instead clustered together both in ABTS and PFRAP, cluster II and Ib respectively, except for the PFRAP, where the stems are included in a separate group, displaying the lowest activity values. A different behaviour was highlighted for the DDPH test, where the lowest values were measured with a progressive decrease in activity from cluster I (bracts and fruits) to the lowest of the III (stems and leaves). The analysed data reveals that the classes of metabolites in the alcoholic extracts, responsible for the observed antioxidant activity, lead to a different response depending on assay used, but mainly on the quali- and quantitative composition of the extracts. In particular, the highest activity of bracts and fruits can be in agreement with the large amount of hydroxycinnamoyl compounds, such as chlorogenic acid and dicaffeoyl quinic acid for bracts, and tricaffeoyl citric acid in fruit extract. In fact, these compounds contain catechol moiety in their structure, which is highly reactive, based on its 
two exchangeable hydrogen atoms. They exhibit an antioxidant activity more than that of glycosylated flavonoids, particularly abundant in the florets extract, since the glycosylation reduces their antioxidant activity when compared to that of their respective aglycones [49].

ABTS
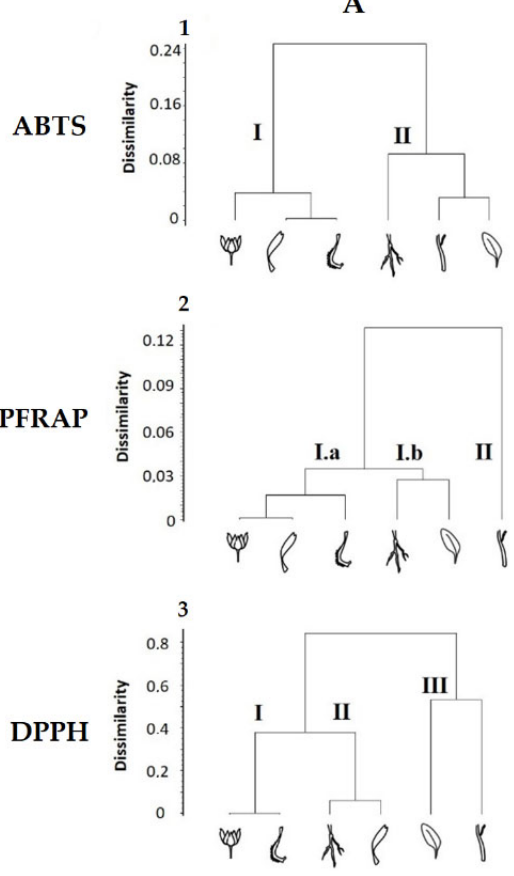
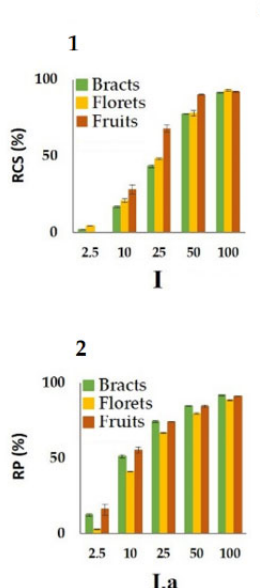

I.a

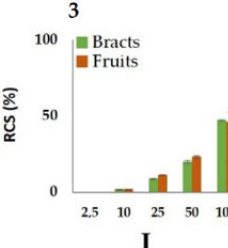

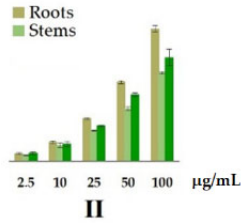

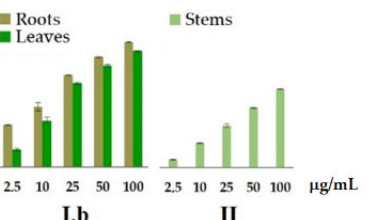

Florets
Roots

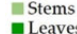

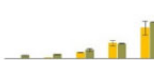

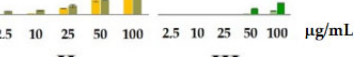

III

Figure 5. Dendrograms (A) and activity (B) from antioxidant assays (ABTS, PFRAP, and DPPH) carried out on the alcoholic extracts of the Calendula arvensis organs. RSC, Radical Scavenging Capacity; RP, Reducing Power. Data are expressed as the mean \pm SD of two experiments, independently carried out, each of which in triplicate.

The interest in the Calendula genus has always been high but, from a scientific point of view, if the chemistry and bioactivity of $C$. officinalis, also elected the herb of the year in 2008 by the International Herb Association [76], have been widely investigated, little attention has been given, if not in local research, to $C$. arvensis. The latter, which could familiarly be referred to as the ugly half-sister of the pot marigold, shares its phytochemical goodness. Although C. arvensis flower and leaf extracts were extensively studied for their antioxidant efficacy [77], our study highlighted that the biological activity commonly ascribed to "flowers" is largely attributable also to a specific part of the inflorescence, including involucral bracts and fruits. Thus, the careful examination of the bioactivity of the different plant parts is also necessary to increase its potential for use [78].

The diversity in flavonol glycosides has not been highlighted before in the few studies conducted, relating to the phytochemical aspects of the species (Figure 6). In this context, an in-depth study of the current literature highlights that a large portion of the compounds identified have not been reported before as constituents of $C$. arvensis, where several studies underline their presence in other species of the same genus, even if different from the more attentive $C$. officinalis. However, recently, some beneficial properties of the C. arvensis are enhancing the need to thoroughly detail its chemical constitution, also with the objective to fully exploit its properties on human and animal health. The hypoglycaemic activity, exerted mainly through enzyme inhibition, of the aqueous and methanolic extracts of $C$. arvensis flowers have been demonstrated [79]. The inhibitory activity against $\alpha-$ amylase, $\alpha$-glucosidase, and $\beta$-galactosidase was ascribed to caffeic acid and its derivatives. Indeed, considering compositive information herein acquired, these compounds are mainly abundant in the fruits of the species. The fruit organ lacks triterpene saponins. The latter were broadly studied for their gastroprotective, antiviral, antimutagenic, and antiinflammatory activities, and their recovery in bracts, as well as in leaves and stems, making 
these organs an exploitable source. In light of this, and taking into account that $C$. arvensis, from an ecological point of view, displays a wide diffusion strategy even outside its original range [23], it is interesting to evaluate that the availability to recover its bioactive compounds could be a tool also to counteract the high weed risk assessment for the species [80]. In this context, and considering process and product sustainability, the chemical compositional study of $C$. arvensis points to new scenarios in which the use of the plant for food and/or nutraceutical purposes is also fully configured. The data acquired provide a valuable tool for revalorizing this wild food species, preserving its traditional uses, and improving the Mediterranean diet assortment.
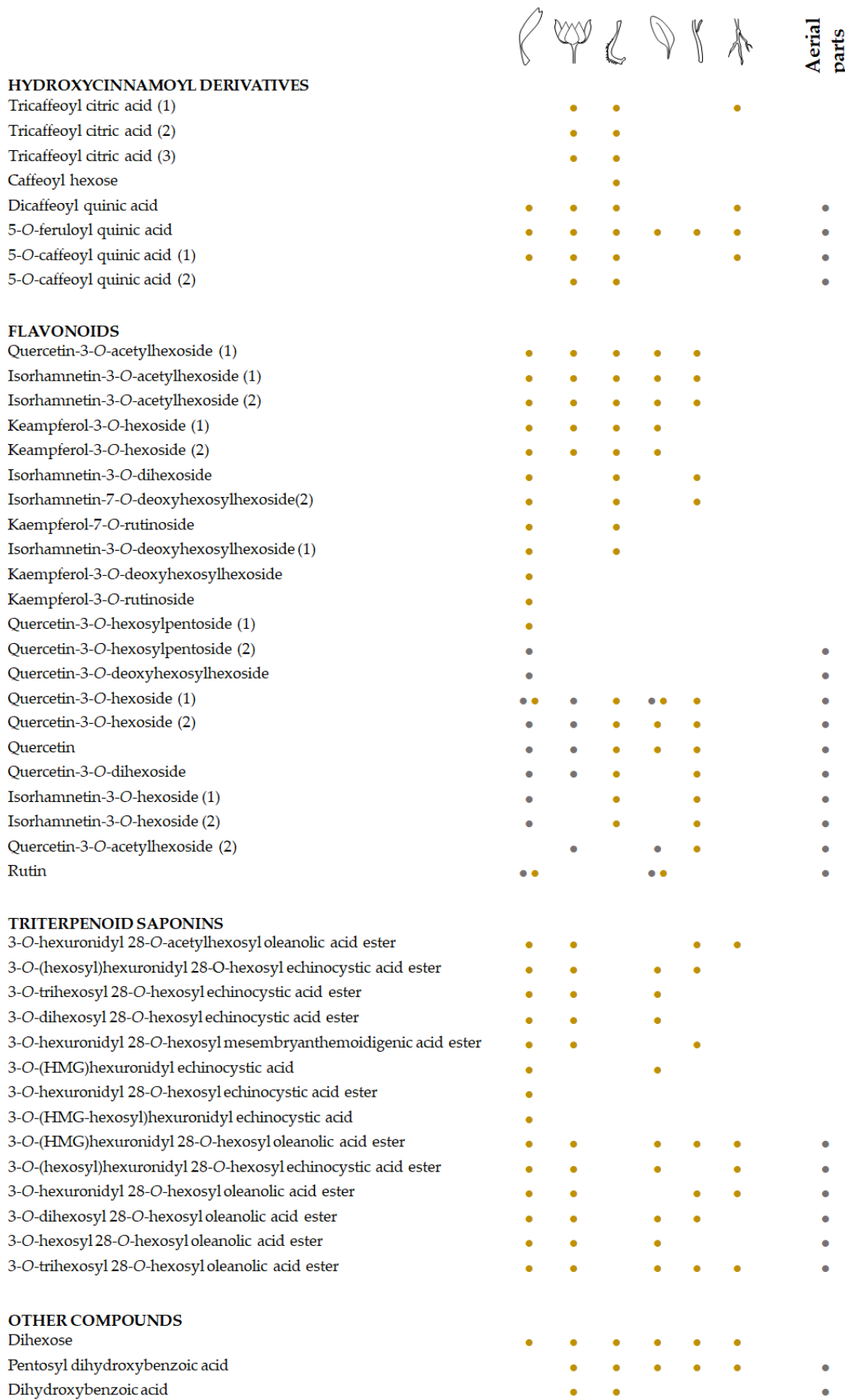

Figure 6. Comparison of the specialized metabolites herein identified in the different organs from Calendula arvensis $(\bullet)$ and in previous literature reports $(\bullet)[38,39,57,65,77]$. 


\section{Conclusions}

Wild edible plants are a great source of bioactive specialized metabolites whose intake could be beneficial for humans, but the knowledge on these plants, broadly consumed as part of local dishes, is still not enough. Wild plants, whose leaves, flowers, or fruits are edible, can be particularly tasty. This is mainly true for the native, pleasant looking species $C$. arvensis (Vaill.) L., which represents a strong competitor in agricultural, anthropogenic, and natural systems. The wide range of distribution and locally high coverage of this species is due to its ability to adapt to different environments, also thanks to its richness in specialized metabolites. Furthermore, considering its local use in the food and cosmetic sectors, the valuable use of all its organs represents a feasible strategy. Herein, the UHPLC-QqTOFMS/MS analysis of the alcoholic extracts from the species organs, properly dissected, has particularly emphasized that the knowledge of the phytochemistry of this species is far from being fully known. On the other hand, since the phytochemical diversity of the various organs is similar to other species of the genus Calendula, which have a more marked economic impact, $C$. arvensis has a potential for use that is not fully exploited. The data acquired highlighted that each organ is a reservoir of specific classes of substances. Not disregarding the botanical role that each organ plays, and investigating finely its composition, fruits, and bracts of $C$. arvensis, which share a great part of hydroxycinnamoyl compounds, are highlighted as a fascinating source for further exploration within and beyond the food field. The research data are a stimulus for further investigation aimed at highlighting, on the one hand, the phytochemical-environmental aspects of this species, also considering its harvesting in different areas, and on the other hand, to deepen the health aspects of its various organs in order to consider the use of $C$. arvensis not only for its florets, which add a touch of color and fragrant aromas to salads or other dishes, or even for its leaves, which could be boiled or not, to vary and/or characterize the flavor of local dishes. Therefore, the data acquired are nothing more than a starting point, and, based on the chemical diversity of the polar constituents, a systematic organ-specific investigation of the apolar component will be pursued.

Supplementary Materials: Supporting information can be downloaded at: https://www.mdpi. com/article/10.3390/foods11030247/s1. Figure S1: (a) TOF-MS/MS spectrum of the compounds (i) 30, (ii) 31, and (iii) 33; (b) tentative fragmentation pathway of the theoretical $[\mathrm{M}-\mathrm{H}]^{-}$ion at $\mathrm{m} / \mathrm{z}$ 695.1254; Figure S2: TOF-MS/MS spectrum of the quercetin glycosides from the florets alcoholic extract (a) 10, (b) 11, (c) 12, (d) 13, (e) 14, (f) 15, (g) 16, and (h) 22. Neutral losses of 324.10 (10 and 12), 294.09 (11 and 14), 308.11 (12 and 15), 162.05 (13 and 16), and 204.06 (22) allowed the glyconic moiety to be recognized; Figure S3: Chemical structures of triterpene saponins (36-49) tentatively identified in the Calendula arvensis alcoholic extracts. Hex, hexose; Hexu, hexuronic acid; Achex, acetylhexose; HMG, Hydroxymethylglutaric acid; Figure S4: (a) TOF-MS/MS spectrum and (b) tentative fragmentation pathway of the theoretical $[\mathrm{M}-\mathrm{H}]^{-}$ion for compound 36. Figure S5: (a) TOF-MS/MS spectrum and (b) tentative fragmentation pathway of the theoretical $[\mathrm{M}-\mathrm{H}]^{-}$ion for compound 37 . Figure S6: (a) TOF-MS/MS spectrum and (b) tentative fragmentation pathway of the theoretical $[\mathrm{M}-\mathrm{H}]^{-}$ion for compound 38. Figure S7: (a) TOF-MS/MS spectrum and (b) tentative fragmentation pathway of the theoretical $[\mathrm{M}-\mathrm{H}]^{-}$ion for compound 39. Figure S8: (a) TOF-MS/MS spectrum and (b) tentative fragmentation pathway of the theoretical $[\mathrm{M}-\mathrm{H}]^{-}$ion for compound 40. Figure S9: (a) TOF-MS/MS spectrum and (b) tentative fragmentation pathway of the theoretical $[\mathrm{M}-\mathrm{H}]^{-}$ion for compound 41. Figure S10: (a) TOF-MS/MS spectrum and (b) tentative fragmentation pathway of the theoretical $[\mathrm{M}-\mathrm{H}]^{-}$ion for compound 42. Figure S11: (a) TOF-MS/MS spectrum and (b) tentative fragmentation pathway of the theoretical $[\mathrm{M}-\mathrm{H}]^{-}$ion for compound 43. Figure S12: (a) TOF-MS/MS spectrum and (b) tentative fragmentation pathway of the theoretical $\left[\mathrm{M}+\mathrm{HCOO}^{-}\right]^{-}$ion for compound 44. Figure S13: (a) TOF-MS/MS spectrum and (b) tentative fragmentation pathway of the $\left[\mathrm{M}+\mathrm{HCOO}^{-}\right]^{-}$ion for compound 45. Figure S14: (a) TOF-MS/MS spectrum and (b) tentative fragmentation pathway of the theoretical $[\mathrm{M}-\mathrm{H}]^{-}$ion for compound 46. Figure S15: (a) TOF-MS/MS spectrum and (b) tentative fragmentation pathway of the $\left[\mathrm{M}+\mathrm{HCOO}^{-}\right]^{-}$ion for compound 47. Figure S16: (a) TOF-MS/MS spectrum and (b) tentative fragmentation pathway of the theoretical 
$[\mathrm{M}-\mathrm{H}]^{-}$ion for compound 48. Figure S17: (a) TOF-MS/MS spectrum and (b) proposed fragmentation pathway of the $[\mathrm{M}-\mathrm{H}]^{-}$ion for compound 49

Author Contributions: Conceptualization, S.P. (Severina Pacifico) and A.E.; methodology, S.P. (Severina Pacifico) and A.E.; validation, M.F. (Marialuisa Formato), M.T.P. and S.P. (Simona Piccolella); formal analysis, C.G.; M.F. (Marika Fiorentino), M.F. (Marialuisa Formato), M.T.P. and S.P. (Simona Piccolella); investigation, C.G., M.F. (Marika Fiorentino), M.F. (Marialuisa Formato), M.T.P. and S.P. (Simona Piccolella); resources, S.P. (Severina Pacifico) and A.E.; data curation, M.F. (Marika Fiorentino), S.P. (Severina Pacifico) and A.E.; writing-original draft preparation, S.P. (Severina Pacifico) and A.E.; writing-review and editing, M.F. (Marialuisa Formato), A.S., S.P. (Severina Pacifico) and A.E.; visualization, A.S., M.F. (Marialuisa Formato) and S.P. (Simona Piccolella); supervision, S.P. (Severina Pacifico); project administration, S.P. (Severina Pacifico) and A.E.; funding acquisition, S.P. (Severina Pacifico). All authors have read and agreed to the published version of the manuscript.

Funding: There was no financial support for the research.

Data Availability Statement: The data are included in this manuscript and in its Supplementary Materials.

Acknowledgments: The authors thank the PON Project "Valorizzazione delle specie officinali della flora autoctona del Parco Nazionale del Cilento, Vallo di Diano e Alburni (PNCVDA)" DOT13499551.

Conflicts of Interest: The authors have no conflict of interest to declare.

\section{References}

1. Łuczaj, Ł.; Pieroni, A. Nutritional Ethnobotany in Europe: From Emergency Foods to Healthy Folk Cuisines and Contemporary Foraging Trends. In Mediterranean Wild Edible Plants; Sánchez-Mata, M., Tardío, J., Eds.; Springer: New York, NY, USA, 2016; pp. 33-56.

2. Ceccanti, C.; Landi, M.; Benvenuti, S.; Pardossi, A.; Guidi, L. Mediterranean Wild Edible Plants: Weeds or "New Functional Crops"? Molecules 2018, 23, 2299. [CrossRef]

3. Rivera, D.; Obon, C.; Inocencio, C.; Heinrich, M.; Verde, A.; Fajardo, J.; Llorach, R. The Ethnobotanical Study of Local Mediterranean Food Plants as Medicinal Resources in Southern Spain. J. Physiol. Pharmacol. 2005, 56, 97-114.

4. Guarrera, P.M.; Savo, V. Perceived Health Properties of Wild and Cultivated Food Plants in Local and Popular Traditions of Italy: A Review. J. Ethnopharmacol. 2013, 146, 659-680. [CrossRef] [PubMed]

5. Mattalia, G.; Quave, C.L.; Pieroni, A. Traditional Uses of Wild Food and Medicinal Plants among Brigasc, Kyé, and Provençal Communities on the Western Italian Alps. Genet. Resour. Crop. Evol. 2013, 60, 587-603. [CrossRef]

6. Trichopoulou, A.; Martínez-González, M.A.; Tong, T.Y.; Forouhi, N.G.; Khandelwal, S.; Prabhakaran, D.; Mozaffarian, D.; de Lorgeril, M. Definitions and Potential Health Benefits of the Mediterranean Diet: Views from Experts around the World. BMC Med. 2014, 12, 112. [CrossRef]

7. Motti, R.; Bonanomi, G.; Lanzotti, V.; Sacchi, R. The Contribution of Wild Edible Plants to the Mediterranean Diet: An Ethnobotanical Case Study Along the Coast of Campania (Southern Italy). Econ. Bot. 2020, 74, 249-272. [CrossRef]

8. Sánchez-Mata, M.C.; Cabrera Loera, R.D.; Morales, P.; Fernández-Ruiz, V.; Cámara, M.; Díez Marqués, C.; Pardo-de-Santayana, M.; Tardío, J. Wild Vegetables of the Mediterranean Area as Valuable Sources of Bioactive Compounds. Genet. Resour. Crop. Evol. 2012, 59, 431-443. [CrossRef]

9. $\quad$ Morales, P.; Ferreira, I.C.F.R.; Carvalho, A.M.; Sánchez-Mata, M.C.; Cámara, M.; Fernández-Ruiz, V.; Pardo-de-Santayana, M.; Tardío, J. Mediterranean Non-Cultivated Vegetables as Dietary Sources of Compounds with Antioxidant and Biological Activity. LWT Food Sci. Technol. 2014, 55, 389-396. [CrossRef]

10. Bacchetta, L.; Visioli, F.; Cappelli, G.; Caruso, E.; Martin, G.; Nemeth, E.; Bacchetta, G.; Bedini, G.; Wezel, A.; van Asseldonk, T.; et al. A Manifesto for the Valorization of Wild Edible Plants. J. Ethnopharmacol. 2016, 191, 180-187. [CrossRef] [PubMed]

11. Stinca, A.; Musarella, C.M.; Rosati, L.; Laface, V.L.A.; Licht, W.; Fanfarillo, E.; Wagensommer, R.P.; Galasso, G.; Fascetti, S.; Esposito, A.; et al. Italian Vascular Flora: New Findings, Updates and Exploration of Floristic Similarities between Regions. Diversity 2021, 13, 600. [CrossRef]

12. Paura, B.; Di Marzio, P.; Salerno, G.; Brugiapaglia, E.; Bufano, A. Design a Database of Italian Vascular Alimurgic Flora (AlimurgITA): Preliminary Results. Plants 2021, 10, 743. [CrossRef] [PubMed]

13. Mason, P.; Lang, T. Sustainable Diets: How Ecological Nutrition Can Transform Consumption and the Food System; Routledge: London, UK; Taylor and Francis Group: New York, NY, USA, 2017.

14. Dwivedi, S.L.; Lammerts van Bueren, E.T.; Ceccarelli, S.; Grando, S.; Upadhyaya, H.D.; Ortiz, R. Diversifying Food Systems in the Pursuit of Sustainable Food Production and Healthy Diets. Trends Plant. Sci. 2017, 22, 842-856. [CrossRef] [PubMed]

15. Jacob, M.M.C.; Paulino Albuquerque, U. Biodiverse Food Plants: Which Gaps Do We Need to Address to Promote Sustainable Diets? Ethnobio. Conserv. 2020, 9, 9. [CrossRef]

16. Chivenge, P.; Mabhaudhi, T.; Modi, A.; Mafongoya, P. The Potential Role of Neglected and Underutilised Crop Species as Future Crops under Water Scarce Conditions in Sub-Saharan Africa. Int. J. Environ. Res. 2015, 12, 5685-5711. [CrossRef] 
17. European Commission Biodiversity Strategy for 2030. Available online: https://ec.europa.eu/environment/strategy/ biodiversity-strategy-2030_en (accessed on 21 December 2021).

18. Kachura, A.; Harris, C.S. An Ethnobotanical Meta-Analysis of North American Medicinal Asteraceae. Botany 2021, 1-11. [CrossRef]

19. Gras, A.; Hidalgo, O.; D’Ambrosio, U.; Parada, M.; Garnatje, T.; Vallès, J. The Role of Botanical Families in Medicinal Ethnobotany: A Phylogenetic Perspective. Plants 2021, 10, 163. [CrossRef] [PubMed]

20. Mandel, J.R.; Dikow, R.B.; Siniscalchi, C.M.; Thapa, R.; Watson, L.E.; Funk, V.A. A Fully Resolved Backbone Phylogeny Reveals Numerous Dispersals and Explosive Diversifications throughout the History of Asteraceae. Proc. Natl. Acad. Sci. USA 2019, 116, 14083-14088. [CrossRef] [PubMed]

21. Gonçalves, A.C.; Castro, S.; Paiva, J.; Santos, C.; Silveira, P. Taxonomic Revision of the Genus Calendula (Asteraceae) in the Iberian Peninsula and the Balearic Islands. Phytotaxa 2018, 352, 1-91. [CrossRef]

22. Arora, D.; Rani, A.; Sharma, A. A Review on Phytochemistry and Ethnopharmacological Aspects of Genus Calendula. Phcog. Rev. 2013, 7, 179. [CrossRef]

23. Ruiz De Clavijo, E. The Reproductive Strategies of the Heterocarpic Annual Calendula arvensis (Asteraceae). Acta Oecol. 2005, 28, 119-126. [CrossRef]

24. Arévalo-Precioso, M.L. Las plantas recolectadas y sinantrópicas. In Estudio de Los Restos Paleo Botànicos 2; Revista ArqueoMurcia: Revista Electrónica de Arqueología de la Región de Murcia; IBADER: Lugo, Spain, 2004; Volume 2.

25. Heyn, C.C.; Joel, A. Reproductive Relationships between Annual Species of Calendula (Compositae). Plant Syst. Evol. 1983, 143, 311-329. [CrossRef]

26. Pignatti, S.; Guarino, R.; La Rosa, M. Flora d'Italia 3; Edagricole: Bologna, Italy, 2018.

27. Pignatti, S.; Guarino, R.; La Rosa, M. Flora d'Italia 4; Edagricole: Bologna, Italy, 2019.

28. Meikle, R.D. Flora Europea; Tutin, T.G., Heywood, V.H., Burges, N.A., Moore, D.M., Valentine, D.H., Walters, S.M., Webb, D.A., Eds.; Cambridge University Press: Cambridge, UK, 1976; Volume 4.

29. Licata, M.; Tuttolomondo, T.; Leto, C.; Virga, G.; Bonsangue, G.; Cammalleri, I.; Gennaro, M.C.; La Bella, S. A Survey of Wild Plant Species for Food Use in Sicily (Italy)—Results of a 3-Year Study in Four Regional Parks. J. Ethnobiol. Ethnomed. 2016, 12, 12. [CrossRef] [PubMed]

30. Belabbes, R.; Dib, M.E.A.; Djabou, N.; Ilias, F.; Tabti, B.; Costa, J.; Muselli, A. Chemical Variability, Antioxidant and Antifungal Activities of Essential Oils and Hydrosol Extract of Calendula arvensis L. from Western Algeria. Chem. Biodivers. 2017, 14, e1600482. [CrossRef]

31. Passalacqua, N.G.; Guarrera, P.M.; De Fine, G. Contribution to the Knowledge of the Folk Plant Medicine in Calabria Region (Southern Italy). Fitoterapia 2007, 78, 52-68. [CrossRef]

32. Maccioni, S.; Flamini, G.; Cioni, P.L.; Bedini, G.; Guazzi, E. Ricerche Etnobotaniche In Liguria. La Riviera Spezzina (Liguria Orientale). Atti Soc. Tosc. Sci. Nat. Mem. Serie B 2008, 115, 77-82.

33. Addis, R.; Cruciani, S.; Santaniello, S.; Bellu, E.; Sarais, G.; Ventura, C.; Maioli, M.; Pintore, G. Fibroblast Proliferation and Migration in Wound Healing by Phytochemicals: Evidence for a Novel Synergic Outcome. Int. J. Med. Sci. 2020, 17, 1030-1042. [CrossRef] [PubMed]

34. Abudunia, A.-M.; Marmouzi, I.; Faouzi, M.E.A.; Ramli, Y.; Taoufik, J.; El Madani, N.; Essassi, E.M.; Salama, A.; Khedid, K.; Ansar, M.; et al. Anticandidal, Antibacterial, Cytotoxic and Antioxidant Activities of Calendula arvensis Flowers. J. Mycol. Med. 2017, 27, 90-97. [CrossRef]

35. Abutaha, N.; Nasr, F.A.; Mohammed, A.Z.; Semlali, A.; Al-Mekhlafi, F.A.; Wadaan, M.A. Calendula arvensis L. as an Anti-Cancer Agent against Breast Cancer Cell Lines. Mol. Biol. Rep. 2019, 46, 2187-2196. [CrossRef]

36. Servi, H.; Vatansever, C.; Doğan, A.; Majeed, V. Antibacterial Activity and Essential Oil Composition of Calendula arvensis L. Int. J. Second. Metab. 2020, 7, 229-236. [CrossRef]

37. Paolini, J.; Barboni, T.; Desjobert, J.M.; Djabou, N.; Muselli, A.; Costa, J. Chemical Composition, Intraspecies Variation and Seasonal Variation in Essential Oils of Calendula arvensis L. Biochem. Syst. Ecol. 2010, 38, 865-874. [CrossRef]

38. Kırmızıbekmez, H.; Bassarello, C.; Piacente, S.; Pizza, C.; Çalış, İ. Triterpene Saponins from Calendula arvensis. Z. Naturforsc. B 2006, 61, 1170-1173. [CrossRef]

39. Faustino, M.V.; Pinto, D.C.G.A.; Gonçalves, M.J.; Salgueiro, L.; Silveira, P.; Silva, A.M.S. Calendula, L. Species Polyphenolic Profile and in Vitro Antifungal Activity. J. Funct. Foods 2018, 45, 254-267. [CrossRef]

40. Falleh, H.; Ksouri, R.; Chaieb, K.; Karray-Bouraoui, N.; Trabelsi, N.; Boulaaba, M.; Abdelly, C. Phenolic Composition of Cynara cardunculus L. Organs, and Their Biological Activities. C. R. Biol. 2008, 331, 372-379. [CrossRef] [PubMed]

41. Riffault, L.; Destandau, E.; Pasquier, L.; André, P.; Elfakir, C. Phytochemical Analysis of Rosa hybrida Cv. 'Jardin de Granville' by HPTLC, HPLC-DAD and HPLC-ESI-HRMS: Polyphenolic Fingerprints of Six Plant Organs. Phytochemistry 2014, 99, 127-134. [CrossRef] [PubMed]

42. Yoo, T.K.; Kim, J.S.; Hyun, T.K. Polyphenolic Composition and Anti-Melanoma Activity of White Forsythia (Abeliophyllum Distichum Nakai) Organ Extracts. Plants 2020, 9, 757. [CrossRef]

43. Rivas-Martinéz, S.; Penas, A.; Dìaz, T.E. Bioclimatic \& Biogeographic Maps of Europe. Available online: https://webs.ucm.es/ info/cif/form/maps.htm (accessed on 20 December 2021). 
44. Di Gennaro, A.; Aronne, G.; De Mascellis, R.; Vingiani, S.; Sarnataro, M.; Abalsamo, P.; Cona, F.; Vitelli, L.; Arpaia, I. Sistemi di Terre della CAMPANIA. Monografia e Carta 1:250.000, Con Legenda; Università degli Studi di Napoli Federico II: Napoli, Italy, 2002.

45. Pacifico, S.; Galasso, S.; Piccolella, S.; Kretschmer, N.; Pan, S.-P.; Marciano, S.; Bauer, R.; Monaco, P. Seasonal Variation in Phenolic Composition and Antioxidant and Anti-Inflammatory Activities of Calamintha nepeta (L.) Savi. Food Res. Int. 2015, 69, 121-132. [CrossRef]

46. Formato, M.; Piccolella, S.; Zidorn, C.; Pacifico, S. UHPLC-HRMS Analysis of Fagus sylvatica (Fagaceae) Leaves: A Renewable Source of Antioxidant Polyphenols. Antioxidants 2021, 10, 1140. [CrossRef]

47. Di Maro, A.; Pacifico, S.; Fiorentino, A.; Galasso, S.; Gallicchio, M.L.; Guida, V.; Severino, V.; Parente, A. Raviscanina wild asparagus (Asparagus acutifolius L.): A nutritionally valuable crop with antioxidant and antiproliferative properties. Food Res. Int. 2013, 53, 180-188. [CrossRef]

48. Podani, J. SYN-TAX 2000:Computer Programs for Data Analysis in Ecology and Systematics; User's Manual; Scientia: Budapest, Hungary, 2001; p. 452.

49. Pacifico, S.; Piccolella, S.; Nocera, P.; Tranquillo, E.; Dal Poggetto, F.; Catauro, M. New Insights into Phenol and Polyphenol Composition of Stevia rebaudiana Leaves. J. Pharm. Biomed. 2019, 163, 45-57. [CrossRef] [PubMed]

50. Takenaka, M.; Yan, X.; Ono, H.; Yoshida, M.; Nagata, T.; Nakanishi, T. Caffeic Acid Derivatives in the Roots of Yacon (Smallanthus sonchifolius). J. Agric. Food Chem. 2003, 51, 793-796. [CrossRef] [PubMed]

51. Dudek, M.K.; Dudkowski, Ł.; Bazylko, A.; Kaźmierski, S.; Kiss, A.K. Caffeic Acid Derivatives Isolated from the Aerial Parts of Galinsoga parviflora and Their Effect on Inhibiting Oxidative Burst in Human Neutrophils. Phytochem. Lett. 2016, 16, 303-310. [CrossRef]

52. Tanaka, Y.; Yagi, M.; Takabe, W.; Sakata, Y.; Yonei, Y. Anti-Glycative Effect of Yogurt: Prevention of Advanced Glycation End Product Formation. Glycative Stress Res. 2017, 4, 25-31.

53. Miguel, M.; Barros, L.; Pereira, C.; Calhelha, R.C.; Garcia, P.A.; Castro, M.Á.; Santos-Buelga, C.; Ferreira, I.C.F.R. Chemical Characterization and Bioactive Properties of Two Aromatic Plants: Calendula officinalis L. (Flowers) and Mentha cervina L. (Leaves). Food Funct. 2016, 7, 2223-2232. [CrossRef] [PubMed]

54. Vidal-Ollivier, E.; Elias, R.; Faure, F.; Babadjamian, A.; Crespin, F.; Balansard, G.; Boudon, G. Flavonol Glycosides from Calendula officinalis Flowers. Planta Med. 1989, 55, 73-74. [CrossRef] [PubMed]

55. Olennikov, D.N.; Kashchenko, N.I. Calendosides I-IV, New Quercetin and Isorhamnetin Rhamnoglucosides from Calendula officinalis. Chem. Nat. Compd. 2014, 50, 633-637. [CrossRef]

56. Olennikov, D.N.; Kashchenko, N.I. New Isorhamnetin Glycosides and Other Phenolic Compounds from Calendula officinalis. Chem. Nat. Compd. 2013, 49, 833-840. [CrossRef]

57. De Tommasi, N.; Conti, C.; Stein, M.; Pizza, C. Structure and in Vitro Antiviral Activity of Triterpenoid Saponins from Calendula arvensis. Planta Med. 1991, 57, 250-253. [CrossRef]

58. Liang, Q.; Qian, H.; Yao, W. Identification of Flavonoids and Their Glycosides by High-Performance Liquid Chromatography with Electrospray Ionization Mass Spectrometry and with Diode Array Ultraviolet Detection. Eur. J. Mass Spectrom. 2005, 11, 93-101. [CrossRef]

59. Choi, S.-J.; Tai, B.H.; Cuong, N.M.; Kim, Y.-H.; Jang, H.-D. Antioxidative and Anti-Inflammatory Effect of Quercetin and Its Glycosides Isolated from Mampat (Cratoxylum formosum). Food Sci. Biotechnol. 2012, 21, 587-595. [CrossRef]

60. Pires, T.C.S.P.; Dias, M.I.; Barros, L.; Calhelha, R.C.; Alves, M.J.; Oliveira, M.B.P.P.; Santos-Buelga, C.; Ferreira, I.C.F.R. Edible Flowers as Sources of Phenolic Compounds with Bioactive Potential. Int. Food Res. J. 2018, 105, 580-588. [CrossRef]

61. Mohammad Sadaka, M.W. A Novel Eudesmane Glycosides Sesquiterpene from Calendula officinalis L. Int. J. Pharmacol. Phytochem. Ethnomed. 2016, 3, 39-45. [CrossRef]

62. Olennikov, D.N.; Kashchenko, N.I.; Chirikova, N.K.; Akobirshoeva, A.; Zilfikarov, I.N.; Vennos, C. Isorhamnetin and Quercetin Derivatives as Anti-Acetylcholinesterase Principles of Marigold (Calendula officinalis) Flowers and Preparations. Int. J. Mol. Sci. 2017, 18, 1685. [CrossRef]

63. Szakiel, A.; Ruszkowski, D.; Janiszowska, W. Saponins in Calendula officinalis L.-Structure, Biosynthesis, Transport and Biological Activity. Phytochem. Rev. 2005, 4, 151-158. [CrossRef]

64. Lehbili, M.; Alabdul Magid, A.; Kabouche, A.; Voutquenne-Nazabadioko, L.; Abedini, A.; Morjani, H.; Sarazin, T.; Gangloff, S.C.; Kabouche, Z. Oleanane-Type Triterpene Saponins from Calendula stellata. Phytochemistry 2017, 144, 33-42. [CrossRef]

65. Pizza, C.; Zhong-Liang, Z.; de Tommasi, N. Plant Metabolites. Triterpenoid Saponins from Calendula arvensis. J. Nat. Prod. 1987, 50, 927-931. [CrossRef]

66. Huang, S.P.; Hsu, H.C.; Liew, C.Y.; Tsai, S.T.; Ni, C.K. Logically Derived Sequence Tandem Mass Spectrometry for Structural Determination of Galactose Oligosaccharides. Glycoconj. J. 2021, 38, 177-189. [CrossRef]

67. Yoshikawa, M.; Murakami, T.; Kishi, A.; Kageura, T.; Matsuda, H. Medicinal Flowers. III. Marigold. (1): Hypoglycemic, Gastric Emptying Inhibitory, and Gastroprotective Principles and New Oleanane-Type Triterpene Oligoglycosides, Calendasaponins A, B, C, and D, from Egyptian Calendula officinalis. Chem. Pharm. Bull. 2001, 49, 863-870. [CrossRef] [PubMed]

68. Li, F.; Li, W.; Fu, H.; Zhang, Q.; Koike, K. Pancreatic Lipase-Inhibiting Triterpenoid Saponins from Fruits of Acanthopanax senticosus. Chem. Pharm. Bull. 2007, 55, 1087-1089. [CrossRef] [PubMed]

69. ChemSpider ISearch and Share Chemistry. Available online: http://www.chemspider.com/ (accessed on 21 September 2021). 
70. Chemli, R.; Babadjamian, A.; Faure, R.; Boukef, K.; Balansard, G.; Vidal, E. Arvensoside A and B, Triterpenoid Saponins from Calendula arvensis. Phytochemistry 1987, 26, 1785-1788. [CrossRef]

71. Vecherko, L.P.; Zinkevich, É.P.; Kogan, L.M. The Structure of Calenduloside F from the Roots of Calendula officinalis. Chem. Nat. Compd. 1973, 9, 532-533. [CrossRef]

72. Jan, N.; Majeed, U.; Andrabi, K.I.; John, R. Cold Stress Modulates Osmolytes and Antioxidant System in Calendula officinalis. Acta Physiol. Plant 2018, 40, 73. [CrossRef]

73. Calvano, C.D.; Cataldi, T.R.I.; Kögel, J.F.; Monopoli, A.; Palmisano, F.; Sundermeyer, J. Structural Characterization of Neutral Saccharides by Negative Ion MALDI Mass Spectrometry Using a Superbasic Proton Sponge as Deprotonating Matrix. J. Am. Soc. Mass Spectrom. 2017, 28, 1666-1675. [CrossRef]

74. Richards, A.B.; Krakowka, S.; Dexter, L.B.; Schmid, H.; Wolterbeek, A.P.M.; Waalkens-Berendsen, D.H.; Shigoyuki, A.; Kurimoto, M. Trehalose: A Review of Properties, History of Use and Human Tolerance, and Results of Multiple Safety Studies. Food Chem. Toxicol. 2002, 40, 871-898. [CrossRef]

75. Matysik, G.; Wójciak-Kosior, M.; Paduch, R. The Influence of Calendulae officinalis Flos Extracts on Cell Cultures, and the Chromatographic Analysis of Extracts. J. Pharm. Biomed. 2005, 38, 285-292. [CrossRef] [PubMed]

76. International Herb Association. Available online: https://iherb.org/ (accessed on 21 December 2021).

77. Ercetin, T.; Senol, F.S.; Erdogan Orhan, I.; Toker, G. Comparative Assessment of Antioxidant and Cholinesterase Inhibitory Properties of the Marigold Extracts from Calendula arvensis L. and Calendula officinalis L. Ind. Crops Prod. 2012, 36, 203-208. [CrossRef]

78. Ak, G.; Zengin, G.; Sinan, K.I.; Mahomoodally, M.F.; Picot-Allain, M.C.N.; Cakır, O.; Bensari, S.; Yılmaz, M.A.; Gallo, M.; Montesano, D. A Comparative Bio-Evaluation and Chemical Profiles of Calendula officinalis L. Extracts Prepared via Different Extraction Techniques. Appl. Sci. 2020, 10, 5920. [CrossRef]

79. Abudunia, A.-M.; Marmouzi, I.; Kharbach, M.; Jemli, M.E.; Sayah, K.; Bouyahya, A.; Al-kaf, A.; Alyahawi, A.; Ansar, M.; Bouklouze, A.; et al. Hypoglycemic Effect of Calendula Arvensis Flowers Is Mediated by Digestive Enzyme Inhibition. Curr. Bioact. Compd. 2020, 16, 588-592. [CrossRef]

80. United States Department of Agriculture. Weed Risk Assessment for Calendula arvensis L. (Asteraceae)-Field Marigold. 2016. Available online: https://www.aphis.usda.gov/plant_health/plant_pest_info/weeds/downloads/wra/Calendula-arvensis.pdf (accessed on 12 November 2021). 